\title{
The impact of zinc oxide particle morphology as an antimicrobial and when incorporated in Poly(3- hydroxybutyrate-co-3-hydroxyvalerate) films for food packaging and food contact surfaces applications.
}

J.L. Castro-Mayorga ${ }^{a}$, M.J. Fabra $^{a}$, A.M. Pourrahimi $^{b}$, R.T. Olsson ${ }^{b}$ and J.M. Lagaron $a_{*}$

${ }^{a}$ Novel Materials and Nanotechnology Group, Institute of Agrochemistry and Food Technology (IATA), CSIC, 46980, Valencia, Spain. *Corresponding author. IATA-CSIC, Avda. Agustín Escardino, 7, 46980, Paterna, Valencia, Spain. Tel.:+34 96 3900022; fax: +34 96 3636301.E-mail address: 1agaron@iata.csic.es

${ }^{b}$ KTH Royal Institute of Technology, School of Chemical Science and Engineering, Fibre and Polymer Technology, SE-100 44 Stockholm, Sweden 


\section{ABSTRACT}

In this work, zinc oxide $(\mathrm{ZnO})$ micron and nano sized-particles with different morphologies were synthesized by aqueous precipitation and evaluated as antimicrobial agents against foodborne pathogens. The most effective bactericide system was selected to prepare active poly(3-hydroxybutyrate-co-3-hydroxyvalerate) (PHBV) films by three different methods: (i) direct melt-mixing, (ii) melt-mixing of preincorporated $\mathrm{ZnO}$ into PHBV18 (18 mol \% valerate content) fiber mats made by electrospinning, and, (iii) as a coating of the annealed electrospun PHBV18/ZnO fiber mats over compression molded PHBV. Results showed that $\mathrm{ZnO}$ successfully improved the thermal stability of the PHBV18, being the preincorporation method the most efficient in mitigating the negative impact that the PHBV18 had on the thermal stability, barrier and optical properties of the PHBV films. Similar behavior was found for the coating structure although this film showed effective and prolonged antibacterial activity against L. monocytogenes. This study highlights the suitability of the PHBV/ZnO nanostructures for active food packaging and food contact surface applications.

KEYWORDS: ZnO, PHBV, Antimicrobial activity, Electrospinning, Active Packaging, Food contact surfaces. 


\section{INTRODUCTION}

Over the last decades, polymer nanocomposites have become key materials in many nanotechnology applications. In this area, polymers reinforced by metal-based nanoparticles are advanced functional materials which have gained considerable attention specifically for the development of active materials containing metal-based nanoparticles. Active materials of particular interest in for instance food packaging involve components that release or absorb substances, from or into the packaged food, or the surrounding environment, thus extending the shelf life of foods (e.g. inhibiting the growth of pathogenic and spoilage microorganism), preventing and/or indicating the migration of contaminants while maintaining or even improving their nutritional quality and ensuring food safety (Ozdemir \& Floros). Recently, the interest in antimicrobial packaging has been increased considerably owing to their ability to eliminate food borne pathogens and to reduce the risks of various food poisoning outbreaks and illnesses (Han, 2000). Inorganic agents, such as $\mathrm{TiO}_{2}, \mathrm{ZnO}, \mathrm{MgO}$ and $\mathrm{CaO}$ (Huang et al., 2000; Sawai et al., 1995, 1998, 1999, 2000; Sawai, 2003) in the form of bulk materials or nanoparticles are being applied in antimicrobial applications (Fang et al., 2006; Jung et al., 2008) because they are not only stable under the high temperatures and pressures that may occur during plastic food packaging processing (Hewitt et al., 2001; Makhluf et al., 2005), but they are also generally regarded as safe for human beings and animals relative to organic compounds.

Among the inorganic antimicrobial agents, zinc oxide $(\mathrm{ZnO})$ nanostructures have emerged as very efficient tool to prevent microbial proliferation on food product due to their activity against a wide range of microorganism (Stiomenov et al., 2002; Sundrarajan et al., 2012).. The high surface to volume ratio of nanoparticles enhance their antibacterial effect at low 
concentrations and, additionally, provides exceptional chemical and physical properties as an additive for plastics for the UV-shielding, deodorizing, antiseptic, and so on.

However, the toxicity mechanism of $\mathrm{ZnO}$ particles is still not well understood and that is why the minimum inhibitory concentration (MIC) ranges from several to hundreds of ppm depending on the antimicrobial test conditions. According to this, it has been demonstrated that the chemical properties of the medium used in the antimicrobial test $(\mathrm{pH}$, ionic composition, organic matter or ionic strength) can affect the aggregation, chemical form and surface charge of particles and therefore their antimicrobial performance (Djurišić, et al.; Talebian, Amininezhad, \& Doudi). Although several studies have been carried out to better understand the antimicrobial activity of $\mathrm{ZnO}$ particles against different Gram-positive and Gram negative bacteria, the antibacterial mechanism of $\mathrm{ZnO}$ is still a matter of intensive research. Besides the release of $\mathrm{Zn}^{2+}$ ions, several mechanisms about the antimicrobial activity of $\mathrm{ZnO}$ has been described in the literature, such as the cell wall damage, the generation of ROS (like superoxide anions, hydroxyl radicals, hydrogen peroxide) as well as the penetration of the cell envelop, among others (Arakha, Saleem, Mallick, \& Jha).

On another hand, it is important to highlight that, in contrast to other metals, $\mathrm{ZnO}$ is one of the five zinc compounds listed as a Generally Recognized as Safe (GRAS) materials by the US Food and Drug Administration (21CFR182.8991) (FDA 2011), being most commonly used as supplement in the fortification of cereal-based foods. However, there are only few studies about the use of $\mathrm{ZnO}$ nanocomposites as an antimicrobial food packaging additive. So far, $\mathrm{ZnO}$ nanoparticles have been mostly added to petroleum-derived polymers such as low density polyethylene (LDPE) (Emamifar, Kadivar, Shahedi, \& Soleimanian-Zad), polypropylene (PP), polyurethane (PU) or polyethylene (PET) using conventional 
incorporation methods as melt mixing or solvent casting. Nevertheless, in accordance to Pérez et al (2012) (Espitia, Soares, Coimbra, de Andrade, Cruz, \& Medeiros), the use of these nanoparticles in biodegradable polymeric matrices, although recent, will be expanded, since the incorporation of $\mathrm{ZnO}$ would improve the performance of the materials.

As renewable and biodegradable polymers, the polyhydroxyalkanoates (PHAs) have attracted interest for active packaging application. However, their usage has been limited by drawbacks such as the high cost of production, brittleness, low thermal stability in the molten state (Plackett \& Siró) as well as their relatively poor barrier properties that could compromise food quality and safety when intended for use in high demanding applications. Regardless of the above, the low barrier performance might convert into a positive aspect when applied for the development of active packaging technologies where controlled release migration is intented.

To the best of our knowledge, in the particular case of polyhydroxyalkanoates (PHA), there are only two works which reported the effect of the $\mathrm{ZnO}$ nanoparticles on the physicochemical properties and antimicrobial activity of poly(3-hydroxybutyrate) (PHB) (A. M. Díez-Pascual \& A. L. Díez-Vicente, 2014) and poly(3-hydroxybutyrate-co-3hydroxyvalerate) (PHBV) and $\mathrm{ZnO}$ composites prepared via solution casting (A. M. DíezPascual, et al.). In another work, Yu et al. (2010) (Yu, Lan, Wang, Fang, \& Sun) and Naphade and Jog (2012) (Naphade \& Jog) conducted pioneering research about the structural and optical properties of $\mathrm{PHBV} / \mathrm{ZnO}$ nanofibers fabricated by the electrospinning technique. Nevertheless, neither the effect that the morphology of $\mathrm{ZnO}$ particles has on the antimicrobial properties against foodborne pathogens nor the effect that the incorporation method has on the physicochemical and antimicrobial properties of the PHBV nanocomposites and multilayer structures were reported. Therefore, the present work is 
focused on the development and characterization of antimicrobial structures of PHBV containing $\mathrm{ZnO}$ for active packaging applications. This work reports, for the first time, the effect of size, morphology and crystalline structure of the $\mathrm{ZnO}$ particles on their antimicrobial activity against the foodborne pathogens Salmonella enterica and Listeria monocytogenes. After selecting the more effective antimicrobial system, PHBV/ZnO nanocomposites of commercial PHBV3 (3\% mol valerate) and mixed microbial culture derived PHBV18 (18\%mol valerate) were prepared by three different methods: (i) direct melt-mixing, (ii) melt-mixing of preincorporated $\mathrm{ZnO}$ into PHBV18 (18 mol \% valerate) fiber mats made by electrospinning, and, (iii) as a coating of the annealed electrospun PHBV18/ZnO fiber mats over compression molded PHBV. The effect of the incorporation method and the PHBV18 / $\mathrm{ZnO}$ addition on the morphological, optical, thermal, mechanical and barrier properties of the resulting active films as well as their influence on the antimicrobial performance were studied in depth throughout this work.

\section{MATERIALS AND METHODS}

\subsection{Materials}

Zinc nitrate hexahydrate $\left(\mathrm{Zn}\left(\mathrm{NO}_{3}\right)_{2} 6 \mathrm{H}_{2} \mathrm{O}, \geq 98\right.$ wt.\%, Sigma Aldrich), zinc acetate dihydrate $\left(\mathrm{Zn}\left(\mathrm{CH}_{3} \mathrm{COO}\right)_{2} \cdot 2 \mathrm{H}_{2} \mathrm{O}, \geq 99 \%\right.$, Sigma Aldrich), sodium hydroxide ( $\geq 98$ wt. $\%$, Sigma Aldrich), were used as received. High resistivity Milli-Q water $(18.2 \mathrm{M} \Omega \mathrm{cm}$ at 25 ${ }^{\circ} \mathrm{C}$ ) was used in all the aqueous reactions. PHBV3 (3 mol \% valerate content) supplied by Tianan Biopolymer (Ningbo, China) and unpurified PHBV18 (18 mol \% valerate) synthesized from mixed microbial cultures fed with cheese whey, according to the method described by Martinez-Abad et al., 2015 (Martínez-Abad, Cabedo, Oliveira, Hilliou, Reis, 
\& Lagarón), were used as polymer matrix. 2,2,2-Trifuoroethanol (TFE, $\geq 99$ wt.\%, Sigma Aldrich) was used as a solvent for the PHBV18.

\subsection{Synthesis of $\mathrm{ZnO}$ particles}

The hexagonal-pyramid $(\mathrm{P}-\mathrm{ZnO})$, star $(\mathrm{S}-\mathrm{ZnO})$, rod $(\mathrm{R}-\mathrm{ZnO})$, and porous ball $(\mathrm{B}-\mathrm{ZnO})$ particles were synthesized by aqueous precipitation. $\mathrm{ZnO}$ nanoparticles with hexagonalpyramid morphology were prepared by an aqueous precipitation method described by Pourrahimi et al. (Pourrahimi, et al., 2014). A $0.2 \mathrm{M}$ zinc acetate aqueous solution (500 $\mathrm{mL}$ ) was mixed with a $0.5 \mathrm{M} \mathrm{NaOH}$ aqueous solution $(500 \mathrm{~mL})$ under vigorous mechanical stirring at $60{ }^{\circ} \mathrm{C}$. For star and ball morphologies, $0.5 \mathrm{M}$ and $1 \mathrm{M} \mathrm{NaOH}$ solution $(250 \mathrm{~mL})$ was added respectively to $0.067 \mathrm{M}$ zinc nitrate solution $(750 \mathrm{~mL})$ at $60^{\circ} \mathrm{C}$ under vigorous stirring. For rod morphology, a $4 \mathrm{M} \mathrm{NaOH}$ solution was added to $0.067 \mathrm{M}$ zinc nitrate solution at $80^{\circ} \mathrm{C}$. The reaction time was set to $1 \mathrm{~h}$ in all cases. The $\mathrm{ZnO}$ particles were purified thrice in Milli-Q water under ultrasonication, dried at $80{ }^{\circ} \mathrm{C}$ and normal pressure, ground to a fine powder with a pestle and mortar and finally dried at $60{ }^{\circ} \mathrm{C}$ and $20 \mathrm{kPa}$ for 2 h.

\subsection{Development of active PHBV films}

\subsubsection{Preparation of nanocomposites}

Nanocomposites based on PHBV3 and hexagonal-pyramid $\mathrm{ZnO}$ nanoparticles (P-ZnO) were fabricated by two different methods. In the first method, PHBV3 pellet (70 wt.\%), unpurified PHBV18 powder (24 wt.\%) and the P-ZnO powder (6 wt.\%) were directly melt mixing in an internal mixer (Brabender Plastograph, Germany) during 5 minutes at $60 \mathrm{rpm}$ and $180^{\circ} \mathrm{C}$ (sample code: PHBVs-D). The second method involved the preincorporation of P-ZnO in PHBV18 electrospun fibers and subsequently the melt blended with PHBV3 pellets at the same mass ratio and processing parameters than the first method (sample 
code: PHBVs-P). For the PHBV18/ZnO ultrathin fiber mats preparation, polymer solutions contained a total solids content of $10 \mathrm{wt} \%$ was prepared as follow: First, the unpurified PHBV18 at 80 wt.\% was dissolved in TFE under magnetic stirring for $4 \mathrm{~h}$ at $50^{\circ} \mathrm{C}$ and cooled down at room temperature. Then, $\mathrm{P}-\mathrm{ZnO}$ nanoparticles were incorporated at the remaining 20 wt. \% and stirred for 12 more hours. Thereafter, the solution was transferred to a $5 \mathrm{~mL}$ glass syringes, connected through PTFE tubes to a stainless steel needle $(0.9 \mathrm{~mm}$ of inner diameter) and processed using a Fluidnatek® LE-10 electrospinning equipment, trademark of the engineering division of Bioinicia S.L. (Valencia, Spain). Processed samples were collected on a stainless-steel plate connected to the cathode of the power supply and oriented perpendicular to the syringe. The distance between the needle and the plate was $17 \mathrm{~cm}$ and the voltage was maintained in the range $10-12 \mathrm{kV}$. All experiments were carried out at room temperature under a steady flow-rate of $5 \mathrm{~mL} / \mathrm{h}$. After electrospinning, the fiber mats were dried at $60^{\circ} \mathrm{C}$ under vacuum for $24 \mathrm{~h}$ to completely remove the solvent and were subsequently used to preparate the nanocomposites.

The blends obtained by melt mixing were compression molded into films using hot plates hydraulic press (Carver 4122 , USA) at $180{ }^{\circ} \mathrm{C}, 1.8 \mathrm{MPa}$ during $5 \mathrm{~min}$. All materials were oven dried at $60^{\circ} \mathrm{C}$ for at least 24 hours prior to the film preparation. The thickness of the films was measured with a digital micrometer (Mitutoyo, Spain, $\pm 0.001 \mathrm{~mm}$ ) by averaging four measurements on each sample.

Neat PHBV3/PHBV18 blends prepared by melt mixing were used as control for comparative purposes (sample code: PHBVs).

\subsubsection{Preparation of coating systems}

In a third approach, PHBV3 films were coated with PHBV18/ZnO ultrathin fiber mats produced by means of the electrospinning technique according to the above description 
(sample code: PHBVs-B). In this case, a post-annealing step was applied to form a continuous film by fiber coalescence. Fiber mats (30 wt $\%$ ) of c.a. $80 \mu \mathrm{m}$ of thickness were placed onto PHBV3 films and the assembly was put in between hot plates hydraulic press (Carver 4122, USA) at $160{ }^{\circ} \mathrm{C}$ during $2 \mathrm{~min}$ (without pressing).

\subsection{Characterization of $\mathrm{ZnO}$ particles and active PHBV films}

\subsubsection{Surface morphology and surface area measurement}

A field emission scanning electron microscope (SEM; Hitachi S-4800) and a transmission electron microscope (TEM; Hitachi HT7700) were used to assess the particle shape and size (diameter) distributions. For the SEM analysis, powder samples were coated with a thin conductive layer of $\mathrm{Pt} / \mathrm{Pd}(60 / 40)$ by a $20 \mathrm{~s}$ sputtering using a current of $80 \mathrm{~mA}$ in a Cressington 208 HR. The size distribution of the particles was assessed by measuring 250 particles using ImageJ (National Institute of Health, Maryland,USA). For crosssection observations, films were cryofractured by immersion of the sample in liquid nitrogen and sputtered with a gold-palladium mixture under vacuum before their examination. Microanalysis and elemental mapping was conducted from SEM images with an EDAX detector.

The Brunauer-Emmett-Teller (BET) method based on nitrogen adsorption/desorption with a Micromeritics ASAP 2000 at $77 \mathrm{~K}$ was used to determine the specific surface area and pore size distribution.

\subsubsection{Optical properties}

The transparency of the films was determined through the surface reflectance spectra in a spectrocolorimeter CM-3600d (Minolta Co., Tokyo, Japan) with a $10 \mathrm{~mm}$ illuminated sample area. Measurements were taken in triplicate for each sample by using both a white and a black background. Film transparency was evaluated through the internal 
transmittance $\left(T_{\mathrm{i}}\right)(0-1$, theoretical range) by applying the Kubelka-Munk theory for multiple scattering to the reflection data (Fabra, Lopez-Rubio, \& Lagaron). Internal transmittance $\left(T_{\mathrm{i}}\right)$ of the films was quantified using eq. (1). In this equation, $R_{0}$ is the reflectance of the film on an ideal black background. Parameters $a$ and $b$ were calculated by equations (2) and (3), where $R$ is the reflectance of the sample layer backed by a known reflectance $R_{\mathrm{g}}$.

$$
\begin{aligned}
T_{i} & =\sqrt{\left(a-R_{0}\right)^{2}-b^{2}} \\
a & =\frac{1}{2}\left(R+\frac{R_{0}-R+R_{g}}{R_{0} R_{g}}\right) \\
b & =\sqrt{\left(a^{2}-1\right)}
\end{aligned}
$$

Moreover, CIE-L* $\mathrm{a}^{*} \mathrm{~b} *$ coordinates (CIE, 1986) were obtained by the infinite reflection spectra of the samples, using D65 illuminant/10 observer. Samples were evaluated per duplicate and three measurements were taken at random locations on each of the studied films.

\subsubsection{Wide Angle X-Ray Diffraction Analysis}

X-ray diffractograms of the powder samples were recorded at room temperature using a PANalytical X'pert Pro MPD diffractometer with a $\mathrm{Cu}-\mathrm{K} \alpha$ source (wavelength $=1.54178$ A) using a $2 \theta$ step size of $0.017^{\circ}$.

\subsubsection{Differential Scanning Calorimetry (DSC)}

Thermal properties of PHBV and its nanocomposites with $\mathrm{P}-\mathrm{ZnO}$ particles were evaluated by DSC using a Perkin-Elmer DSC 8000 thermal analysis system under nitrogen atmosphere. The sample treatment consisted of a first heating step from $0^{\circ} \mathrm{C}$ to $200^{\circ}$, a subsequent cooling down to $-50^{\circ} \mathrm{C}$ and a second heating step up to $200^{\circ} \mathrm{C}$. The heating and cooling rates for the runs were $10^{\circ} \mathrm{C} / \mathrm{min}$ and the typical sample weight was $\sim 3 \mathrm{mg}$. The 
first melting endotherm, and the controlled crystallization at $10^{\circ} \mathrm{C} / \mathrm{min}$ from the melt, was analyzed. To ensure reliability of the data obtained, heat flow and temperature were calibrated using indium as a standard. The degree of crystallinity (X) was estimated from the corrected enthalpy for total PHBV content in the nanocomposites samples, using the ratio between the enthalpy of the studied material and the enthalpy of a perfect PHBV crystal as expressed by eq. (4), where $\Delta H_{m}$ is the melting enthalpy of the studied specimen, $\Delta H_{m}^{\circ}$ is the melting entalphy of a perfect PHBV crystal (109 J/g (Scandola, et al.)) and $w$ is the weight fraction of the filler. The tests were done, at least, in triplicate.

$X=\frac{\Delta H_{m}}{\Delta H_{m}^{\circ}(1-w)}(4)$

\subsubsection{Thermogravimetric Analysis (TGA)}

Thermogravimetric analysis (TGA) was performed under nitrogen atmosphere in a Perkin Elmer Thermobalance TGA 7. The samples were heated from $30^{\circ} \mathrm{C}$ to $600{ }^{\circ} \mathrm{C}$ at a heating rate of $10^{\circ} \mathrm{C} / \mathrm{min}$. All tests were carried out in duplicate.

\subsubsection{Mechanical properties}

Tensile tests were performed according to ASTM Standard D638 (ASTM 2010) in stamped dumbbell-shaped specimens of the samples. An Instron Testing Machine (Model 4469; Instron Corp., Canton, MA, USA) was used, with a crosshead speed of $10 \mathrm{~mm} / \mathrm{min}$, at ambient conditions of typically $24^{\circ} \mathrm{C}$ and $50 \% \mathrm{RH}$. Elastic modulus, tensile strength, and elongation at break were determined from the stress-strain curves, estimated from forcedistance data obtained for the different films. At least, three specimens of each film were tensile tested as to obtain statistically meaningful results.

\subsubsection{Water Vapour Permeability (WVP)}


Water vapour permeability (WVP) was determined according to the ASTM E96 (ASTM 2011) gravimetric method, using Payne permeability cups (Elcometer SPRL, Hermelle/s Argenteau, Belgium). Cells containing distillate water were placed inside a desiccator at $0 \% \mathrm{RH}$ and $24^{\circ} \mathrm{C}$ and the water weight loss through a film area of $0.001 \mathrm{~m}^{2}$ was monitored. WVP was calculated from the steady-state permeation slopes obtained from the regression analysis of weight loss data over time. All measurements were performed in triplicate.

\subsubsection{Oxygen transmission rate (OTR) measurements}

The oxygen permeability coefficient was derived from oxygen transmission rate (OTR) measurements recorded using an Oxygen Permeation Analyzer M8001 (Systech Illinois, UK). Experiments were carried out at $23^{\circ} \mathrm{C}$ and $80 \% \mathrm{RH}$. The samples were previously purged with nitrogen in the humidity equilibrated samples, before exposure to an oxygen flow of $10 \mathrm{~mL} \mathrm{~min}^{-1}$. The exposure area during the test was $5 \mathrm{~cm}^{2}$ for each sample. In order to obtain the oxygen permeability, film thickness and gas partial pressure were considered in each case. The measurements were done in triplicate.

\subsection{Antimicrobial activity of $\mathrm{ZnO}$ particles and nanocomposites}

The frequent foodborne pathogens, Salmonella enterica CECT 4300 and Listeria monocytogenes CECT 7467 were obtained from the Spanish Type Culture Collection (CECT: Valencia, Spain) and stored in phosphate buffered saline (PBS, Sigma Aldrich ) with 10 wt.- $\%$ tryptic soy broth (TSB, Conda Laboratories ) and 10 wt.- $\%$ glycerol at $-80^{\circ} \mathrm{C}$ until needed. For experimental use, the stock culture was maintained by regular subculture to tryptone soy agar (TSA) slants at $4^{\circ} \mathrm{C}$ and transferred monthly. Previous to each antimicrobial assay, a loopful of bacteria was transferred to $10 \mathrm{~mL}$ of TSB and incubated at $37^{\circ} \mathrm{C}$ overnight and an aliquot was again transferred to TSB and grown at $37^{\circ} \mathrm{C}$ and 120 rpm to the mid-exponential phase of growth and this cultured was used as inoculum. 
Firstly, susceptibility test were performed employing the macro-dilution method described by the Clinical and Laboratory Standard Institute (M26-A). To this end, four $1000 \mathrm{ppm}$ stock suspensions (corresponding to the each of the four different $\mathrm{ZnO}$ particle morphologies) were prepared using Milli-Q water as solvent and the nonionic surfactant Tween 80 (20 wt.\% respect to $\mathrm{ZnO}$ content) in order to facilitate the particles dispersion. Then, $7.5 \mathrm{~mL}$ of each $\mathrm{ZnO}$ suspensions were added into $2.5 \mathrm{~mL}$ TSB medium and subsequently inoculated with a bacterial suspension to achieve an initial inoculum size of ca. $5^{*} 10^{5} \mathrm{CFU} / \mathrm{mL}$. The test tubes were incubated at $37^{\circ} \mathrm{C}$ for $24 \mathrm{~h}$ in a shaking bath at 100 rpm and samples were enumerated by conventional plate count on TSA.

Once the more effective $\mathrm{ZnO}$ particle was selected and incorporated into PHBV films, the antimicrobial activity of the films against Listeria monocytogenes was evaluated following the Japanese Industrial Standard JIS Z 2801. Briefly, a microorganism suspension containing about $5 \times 10^{5} \mathrm{CFU} / \mathrm{mL}$ was inoculated onto the surface of the tested films with a square size of $3 \times 3 \mathrm{~cm}$ and covered with an inert piece of Low-Density Polyethylene (LDPE) of $2.5 \times 2.5 \mathrm{~cm}$ and $80 \mu \mathrm{m}$ of thickness. Then the samples were introduced into Petri dishes and incubated at $24^{\circ} \mathrm{C}$ and at a relative humidity of at least $95 \%$ for $24 \mathrm{~h}$. After the incubation time, the bacteria were recovered and enumerated by conventional plate count. The PHBV films (without $\mathrm{ZnO}$ ) were used as a negative control. The value of the antimicrobial activity (R) was calculated by determining $\log _{10}\left(\mathrm{~N}_{0} / \mathrm{N}_{\mathrm{t}}\right)$, where $\mathrm{N}_{0}$ is the average of the number of viable cells of bacteria on the untreated test piece after $24 \mathrm{~h}$ and $\mathrm{N}_{t}$ is the average of the number of viable cells of bacteria on the antimicrobial test piece after $24 \mathrm{~h}$. Three replicate experiments were performed for each sample.

The antimicrobial activity of the active PHBV films was determined as described above, both in freshly made films ( 0 washes) and after successive washes (5, 10 and 15 washes). 
The films were completely immersed in $5 \mathrm{~mL}$ of sterilized Milli-Q water during time intervals of 5 minutes and then inoculated in order to study the effect of washing on the availability of zinc in each methodology of incorporation (direct, preincorporation and coating structure).

The morphological changes in L. monocytogenes after $24 \mathrm{~h}$ exposure to $750 \mathrm{ppm}$ of $\mathrm{P}-\mathrm{ZnO}$ were further examined by TEM. To this purpose, untreated and $\mathrm{P}-\mathrm{ZnO}$ treated bacteria were fixed, dehydrated and embedded into LR-White resin, following which were cut with an ultramicrotome (Leica UC6) and positively stained with uranylacetate and lead citrate. A Jeol 1010 microscope (Hitachi) equipped with a digital Bioscan (Gatan) image acquisition system at an accelerating voltage of $80 \mathrm{kV}$ was used for the observation.

\subsection{Determination of zinc content}

The estimation of $\mathrm{Zn}$ content in the washing water from successive washes was carried out by inductively coupled plasma- optical emission spectroscopy (ICP-OES, Perkin-Elmer, USA) using a zinc standard solution (traceable to SRM from NIST, $\mathrm{Zn}\left(\mathrm{NO}_{3}\right)_{2}$ in $\mathrm{HNO}_{3} 2-3$ $\% 1000$ mg/L Zn Certipur®, Merck, Germany) for calibration. All measurements were done, in triplicate.

\subsection{Statistical analysis}

The statistical analysis of physico-chemical and antimicrobial data was carried out by means of StatGraphics Plus version 5.1 (Statistical Graphics Corp.) through the analysis of variance (ANOVA). Tukey's Honestly Significant Difference (HSD) was used at the 95\% confidence level for multiple comparison tests. 


\section{RESULTS}

\subsection{Morphology of $\mathrm{ZnO}$ particles}

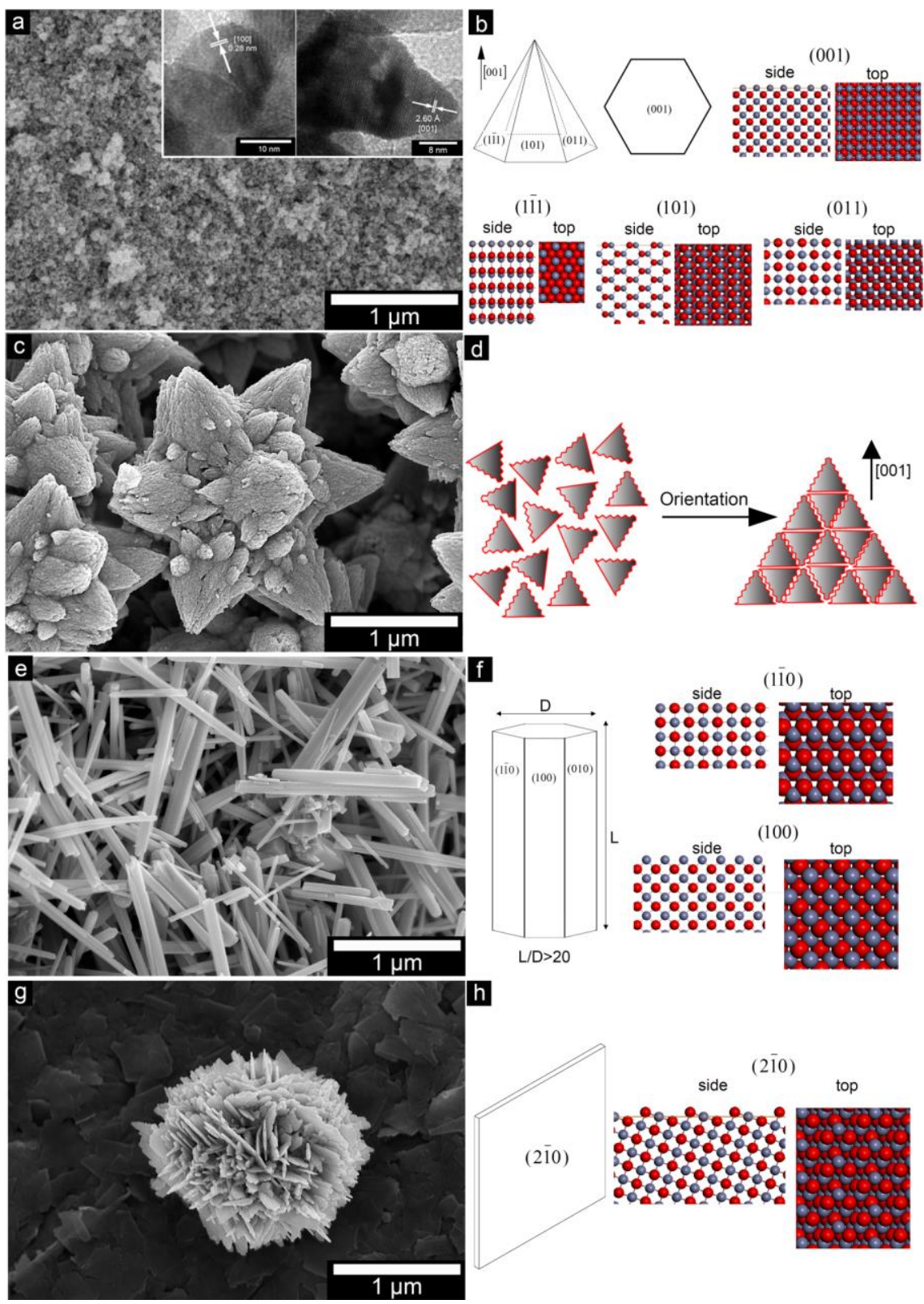

Figure 1. SEM micrographs of $\mathrm{ZnO}$ particles and crystal model of different planar terminations. (a-b) P-ZnO, (c-d) S-Zn), (e-f) R-ZnO, (g-h) B-ZnO. 
Fig. 1 presents the scanning electron micrographs of $\mathrm{ZnO}$ particles together with the crystal model of different planar terminations. The $25 \mathrm{~nm}$ acetate derived hexagonal-pyramid nanoparticles (P-ZnO) had surfaces (Fig. 1a) consisting of basal planes of zinc terminated (001) and zinc enriched $\{101\}$ prismatic planes (Gurlo, 2011; Pourrahimi, et al., 2014), see Fig 1 b. The particles have ca. $74 \%$ of its surfaces terminated by zinc and the rest oxygen, considering the representation of the specific atoms in the prismatic crystal planes, which had a specific surface area of $34 \mathrm{~m}^{2} \mathrm{~g}^{-1}$ (Pourrahimi, Liu, Ström, Hedenqvist, Olsson, \& Gedde, 2015)

On the self-assembly of the prisms to star-shaped particles (Fig. 1c), which occurred with the use of a different zinc salt precursor (to a nitrate salt), not only the specific surface area decreased to $14 \mathrm{~m}^{2} \mathrm{~g}^{-1}$, (Pourrahimi, et al., 2015) but also the percentage of zinc termination since the assembly of the larger particles relied primarily on merging the $100 \%$ zinc enriched basal planes along c-axis during synthesis (Pourrahimi, et al., 2014) (Fig. 1d). The surface of star-shaped particles were therefore terminated by both zinc and oxygen atoms and the fraction of zinc representation decreased to $67 \%$ of the measured $14 \mathrm{~m}^{2} \mathrm{~g}^{-1}$. A large portion of this surface was however embedded inside the porous star-shaped particles (Fig. $1 \mathrm{c}$ and d), since the specific surface area of $2 \mu \mathrm{m}$ particles (Fig 1c) can only be expected to be within the range of $0.4-0.6 \mathrm{~m}^{2} \mathrm{~g}^{-1}$, considering the diameters of the entire particles. This was further confirmed by nitrogen sorption experiments (BET), which showed an average pore size of $3.5 \mathrm{~nm}$ for the star-shaped particles.

Fig. 1e and $\mathrm{f}$ show the scanning electron micrograph of hexagonal rod $\mathrm{ZnO}$ particles (average length: $1 \mu \mathrm{m}$ ) with ca. 20 in aspect ratio, obtained by a modified zinc nitrate precipitation. The high aspect ratio rod particles exhibits dominantly $\{100\}$ crystal planes 
parallel to c-axis; (100) and (010) faces were terminated with zinc atoms, however, (110) face was terminated with both zinc and oxygen atoms,(Gurlo, 2011) Fig. 1f, resulting in a total zinc termination of $83 \%$ of a calculated total surface area of $14 \mathrm{~m}^{2} \mathrm{~g}^{-1}$.

The more complex hierarchical microstructure of the ball-like morphology $\mathrm{ZnO}$ particles that rely on the assembly of $25 \mathrm{~nm}$ thick interleaving sheets with dominant crystal plane of (210) (Li \& Wang, 2010) are shown in Fig. 1g. The interconnected sheets are characterized by $33 \%$ zinc occupancy in their lattice (Fig. 1h), which was present on a measured surface area (BET) of $17 \mathrm{~m}^{2} \mathrm{~g}^{-1}$. The nature of the interconnected surfaces inside the particles are, however, presently unknown.

$\mathrm{X}$-ray diffractograms of the $\mathrm{ZnO}$ particles all showed a single phase $\mathrm{ZnO}$ with clear diffraction peaks corresponding to the lattice planes in the wurzite with a hexagonal cell structure, and crystallographic parameters of $\mathrm{a}=\mathrm{b}=3.254 \AA, \mathrm{c}=5.210 \AA, \alpha=\beta=90^{\circ} ; \gamma=$ $120^{\circ}$ (inorganic crystal structure database; collection code \# 067849). The absence of any amorphous halo and the sharpness of the peaks characteristic of $\mathrm{ZnO}$ indicated high purity for all the particles (data not reported). 


\subsection{Antimicrobial activity of $\mathrm{ZnO}$ particles}

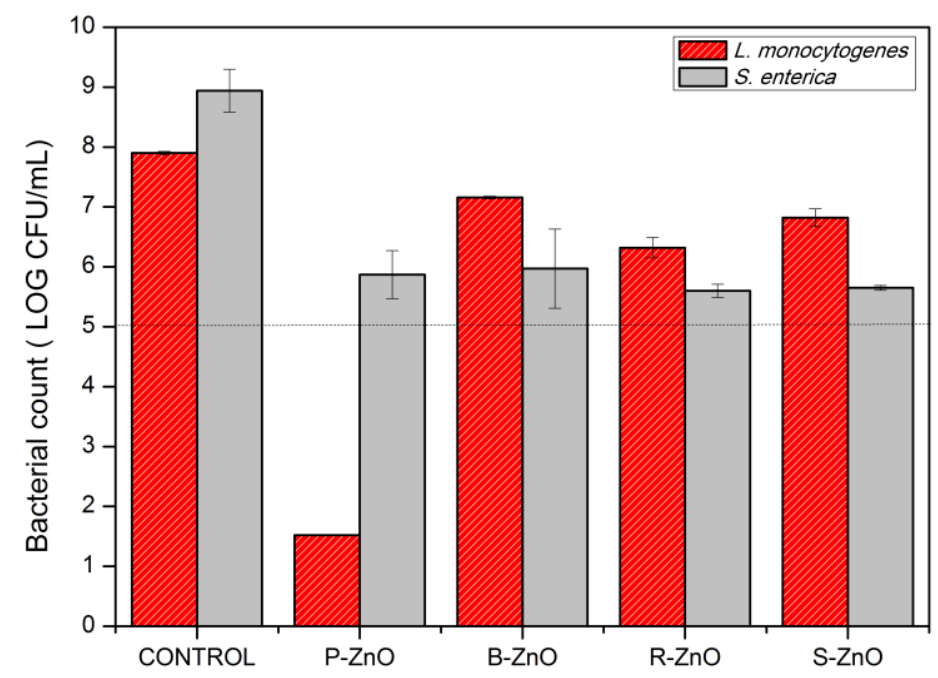

Figure 2. Antimicrobial activity of $\mathrm{ZnO}$ particles against Salmonella enterica and Listeria monocytogenes after $24 \mathrm{~h}$ exposure. The dashed line depicts the initial inoculum size of 5 $\log \mathrm{CFU} / \mathrm{mL}$. The detection limit was $20 \mathrm{CFU} / \mathrm{mL}$.

In the first part of this work, the antimicrobial activity of $\mathrm{ZnO}$ particles against two of the most common pathogenic bacteria (Salmonella enterica and Listeria monocytogenes) involved in foodborne outbreaks was evaluated. Figure 2 reflects the viability of the tested bacteria when incubated in TSB medium. While control samples without $\mathrm{ZnO}$ particles allow an increase of more than $2.5 \log$ units of the bacterial population after $24 \mathrm{~h}$, in all tested tubes containing $\mathrm{ZnO}$ particles, both bacteria were unable to grow or even decreased in number. An inhibition of growth during $24 \mathrm{~h}$ incubation (defined as bacteriostatic effect) 
occurred in S. enterica and L. monocytogenes tests for $\mathrm{S}-\mathrm{ZnO}, \mathrm{R}-\mathrm{ZnO}$ and $\mathrm{B}-\mathrm{ZnO}$ particles while a noticeable bactericidal effect (with a reduction of $>6 \log$ units) against $L$. monocytogenes was achieved for $750 \mathrm{ppm}$ of $\mathrm{P}-\mathrm{ZnO}$. The differences in the antimicrobial performance of the four $\mathrm{ZnO}$ morphologies could be related, on the one hand, to a larger particle effective surface area which enhanced the surface reactivity, and on the other hand, to the different configuration of the zinc ions in the lattice of the crystals (Talebian, et al.). In the present work, the antibacterial activity of $\mathrm{ZnO}$ seemed to improve when the particle size decreased to the nanosize, which means that the surface area increased being the P$\mathrm{ZnO}$ nanoparticles which resulted in the highest antibacterial effect. As commented above, the toxicity mechanism of $\mathrm{ZnO}$ particles is currently controversial and although several studies have been carried out to better understand the antimicrobial activity of $\mathrm{ZnO}$ particles against different Gram-positive and Gram negative bacteria, the antibacterial mechanism of $\mathrm{ZnO}$ is still a matter of intensive research. In general, it can be assumed that the different behavior of the two types of bacteria used in the present work could be also ascribed to the different structural and chemical composition of the cell surfaces of Gramnegative and Gram-positive bacteria. As an example, Figure 4 shows representative images of the cell damage caused by $\mathrm{P}-\mathrm{ZnO}$ on L. monocytogenes after $24 \mathrm{~h}$ of incubation. As can be seen in Figure 3a, untreated bacteria had an intact cell structure while no integral cells were observed in the $\mathrm{P}-\mathrm{ZnO}$ sample ( $c f$ Fig $3 \mathrm{~b}$ ). In the treated cells, an electron-light region appeared in the cytoplasm (indicated by asterisk in Fig 3b) which was not present in the untreated cells. These differences suggest an impact in the lumping and lysis of the cytoplasm cell. Similar effects of $\mathrm{ZnO}$ nanoparticles on E. coli and B. subtilis were previously shown by Brayner et al. (Brayner, Ferrari-Iliou, Brivois, Djediat, Benedetti, \& Fiévet) and by Vidic et al. (Vidic, et al.), respectively. 

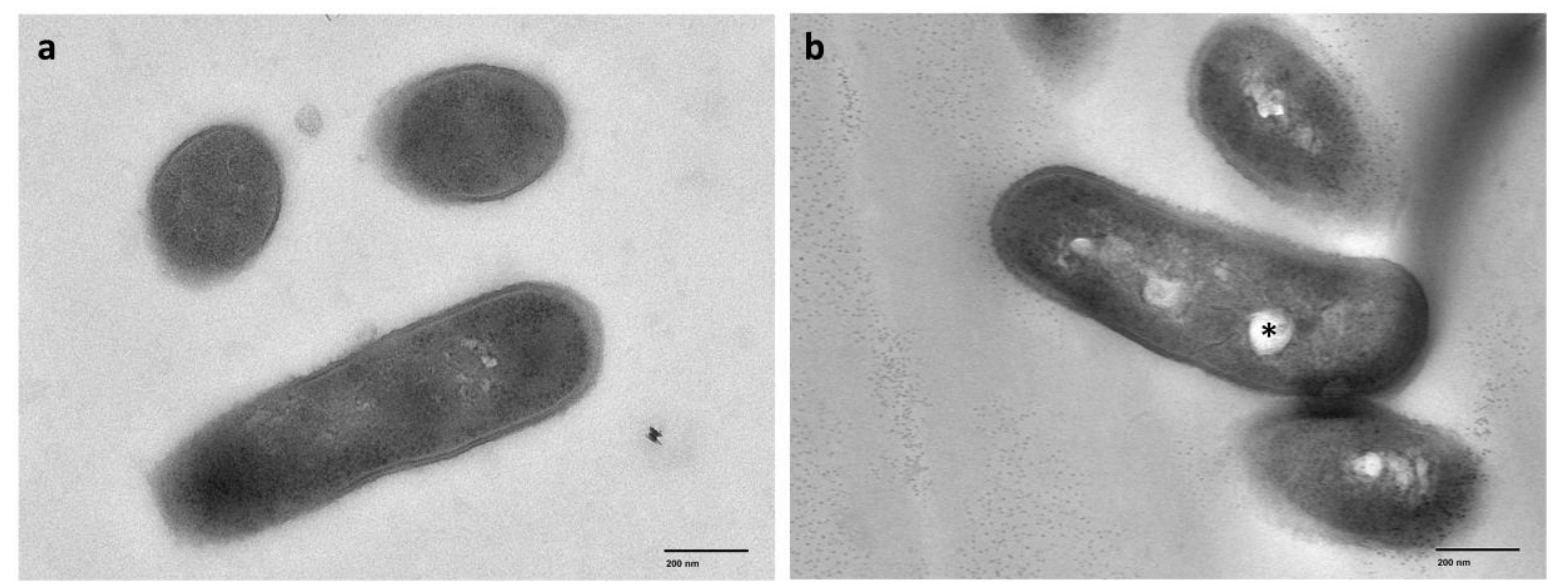

Figure 3. TEM images of Listeria monocytogenes after $24 \mathrm{~h}$ of incubation. (a) Untreated cells, (b) Cells treated with $750 \mathrm{ppm}$ of $\mathrm{P}-\mathrm{ZnO}$ nanoparticles. The electron-light region indicated by asterisk in Fig $4 \mathrm{~b}$ shows the morphological changes in the cytoplasm of treated cells.

\subsection{Development of active PHBV films}

Once the antibacterial performance of each type of $\mathrm{ZnO}$ particles was determined, $\mathrm{P}-\mathrm{ZnO}$ nanoparticles were selected as the most effective antimicrobial morphology to prepare antimicrobial PHBV/P-ZnO films in three different forms described above: (i) direct meltmixing, (ii) melt-mixing of preincorporated $\mathrm{ZnO}$ into PHBV18 (18 mol \% valerate) fiber mats made by electrospinning, and, (iii) as a coating of the annealed electrospun PHBV18/ZnO fiber mats over compression molded PHBV. The physicochemical and antimicrobial properties of the resulting films are presented below.

\subsubsection{Morphology and optical properties}



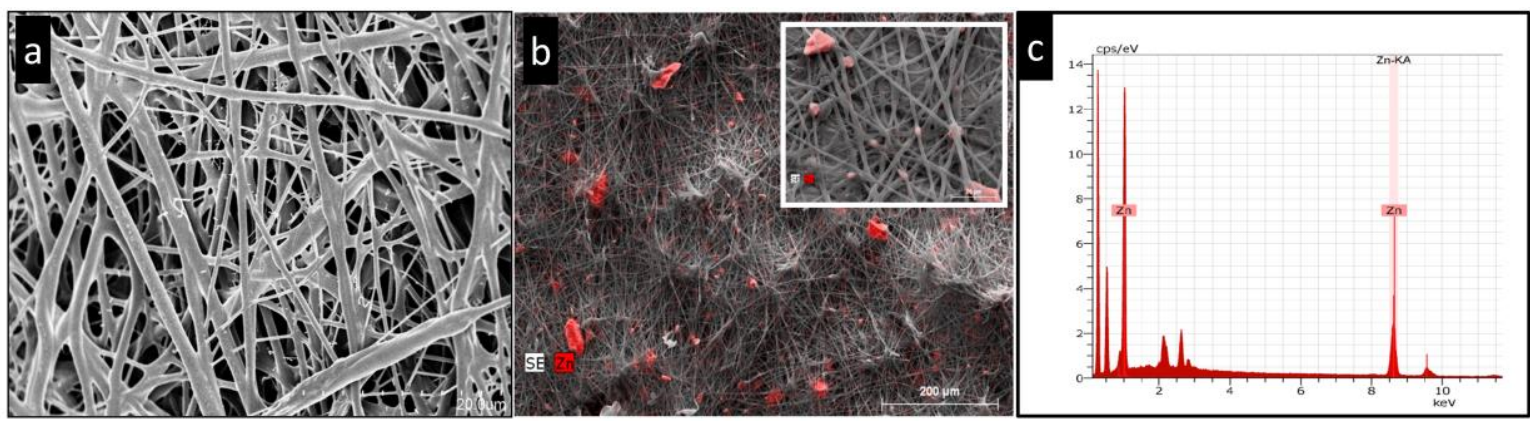

Figure 4. SEM micrographs of electrospun PHBV18: (a) PHBV18 without ZnO. (b) PHBV18 with P-ZnO incorporated by electrospinning. An elemental map analisys for zinc was carried out using EDAX on SEM micrographs, the results of mapping are shown in red. The insert shows a detailed image of fibres containing P-ZnO. (c) EDAX spectra of PHBVs and ZnO-based film. 

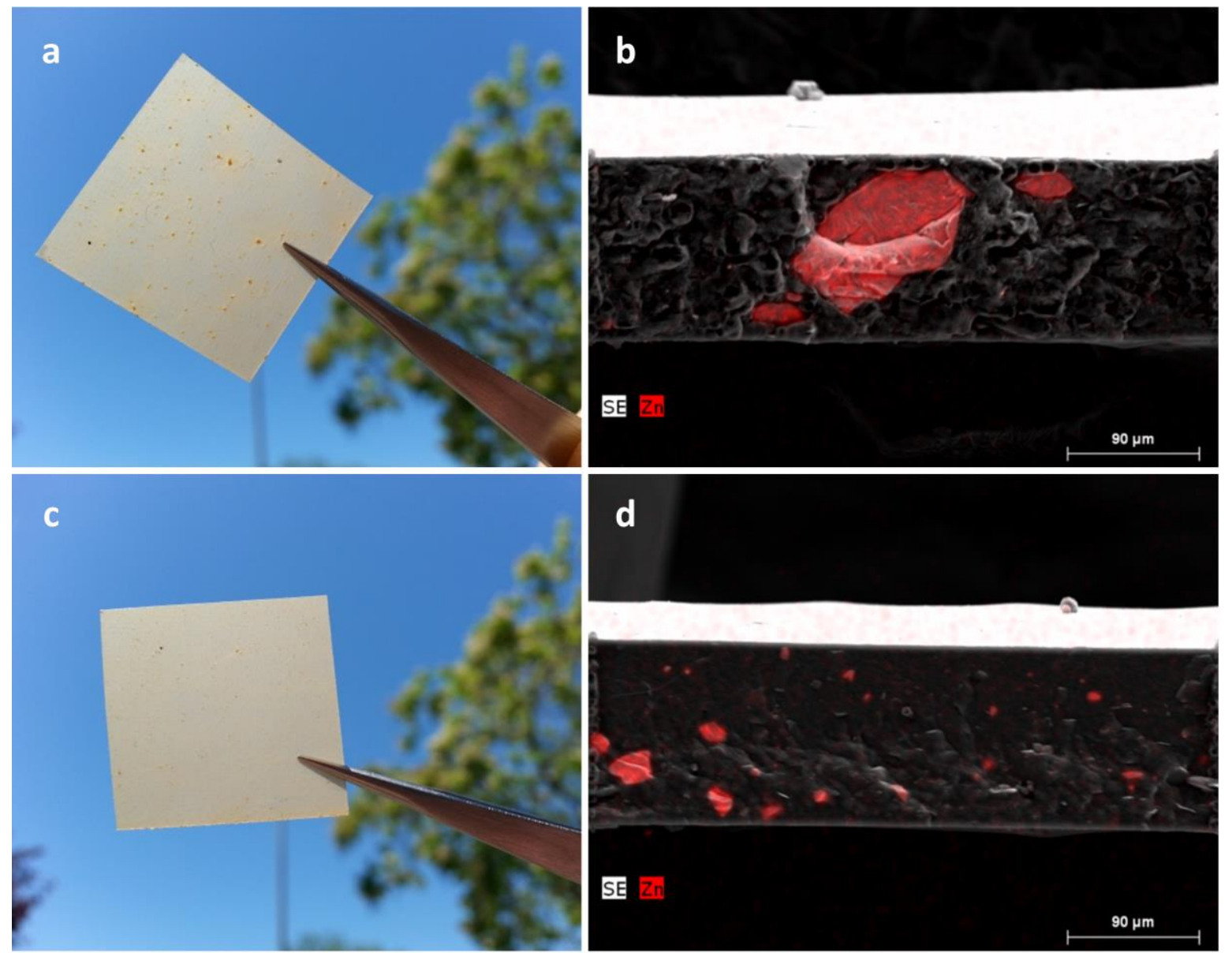

e
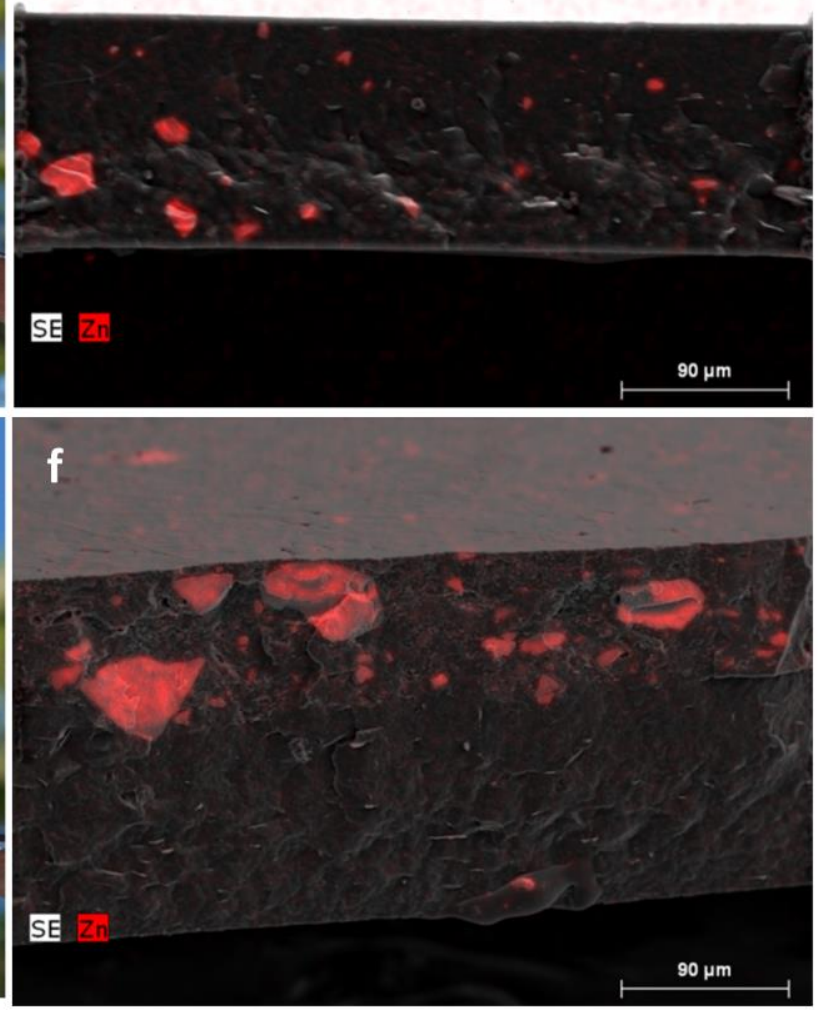

Figure 5. Contact transparency pictures of PHBVs-ZnO films (right column) and their

SEM micrographs (left column) showing the elemental mapping for zinc (in red). (a-b) PHBVs-D, (c,d) PHBVs-P, (c) PHBVs-C. 
In order to characterize the morphology of the PHBV18 composite structures obtained by electrospinning, the fibers mat was observed by SEM. Figure 4 shows the surface morphology of the electrospun PHBV18 without and with $\mathrm{P}-\mathrm{ZnO}$ nanoparticles $(c f$. Fig 4a and $4 \mathrm{~b}$, respectively), where no substantial differences were observed between the samples. The presence of $\mathrm{ZnO}$ in the electrospun mat was confirmed by EDAX analysis ( $c f$. Fig 4c) and the dispersion of $\mathrm{P}-\mathrm{ZnO}$ nanoparticles within the fibers was assessed by SEM-mapping. Figure $4 \mathrm{~b}$ and its inset show a representative and detailed picture of the PHBV18 fibers containing 6 wt.-\% P-ZnO. Although some agglomerates can be discerned from the SEM micrographs, most of the $\mathrm{P}-\mathrm{ZnO}$ nanoparticles are thought to be properly dispersed and distributed within the PHBV18 fibers as it will be later confirmed by examination of the morphology of the PHBVs/P-ZnO nanocomposites. It is worth noting that for the nanocomposites prepared by direct melt mixing, big agglomerates can be clearly discerned in both visual examination ( $c f$. Fig 5a) and SEM micrographs ( $c f$. Fig 5b), hence indicating that this method led to a poorer dispersion of the nanoparticles within the biopolymer matrix. However, when nanocomposites were prepared by means of the preincorporation method ( $c f$. Fig 5c), better contact transparency was observed, in turn suggesting a better dispersion of the P-ZnO into the PHBVs matrices. This was further suggested by SEM micrographs $(c f .5 \mathrm{~d})$ where $\mathrm{ZnO}$ particles were found to be highly dispersed into the polymeric matrix. Concerning the coating system, it can be easily distinguished a laminatelike structure in which the PHBV18/P-Zn-O fibrous layer ( $c f$. Fig. 5e and 5f) formed a continuous coating of $c a .80 \mu \mathrm{m}$ of thickness onto the top side of the PHBV3 layer, showing good adhesion between them. It is also worth highlighting that although some P$\mathrm{ZnO}$ aggregates could be still detected in the PHBVs-P and PHBV-C films, they were smaller than those observed in the PHBVs-D films. The optical images support the best 
dispersion and distribution of the $\mathrm{ZnO}$ nanoparticles in the PHBVs-P and PHBV-C systems (see contact transparency images, Figure 5).

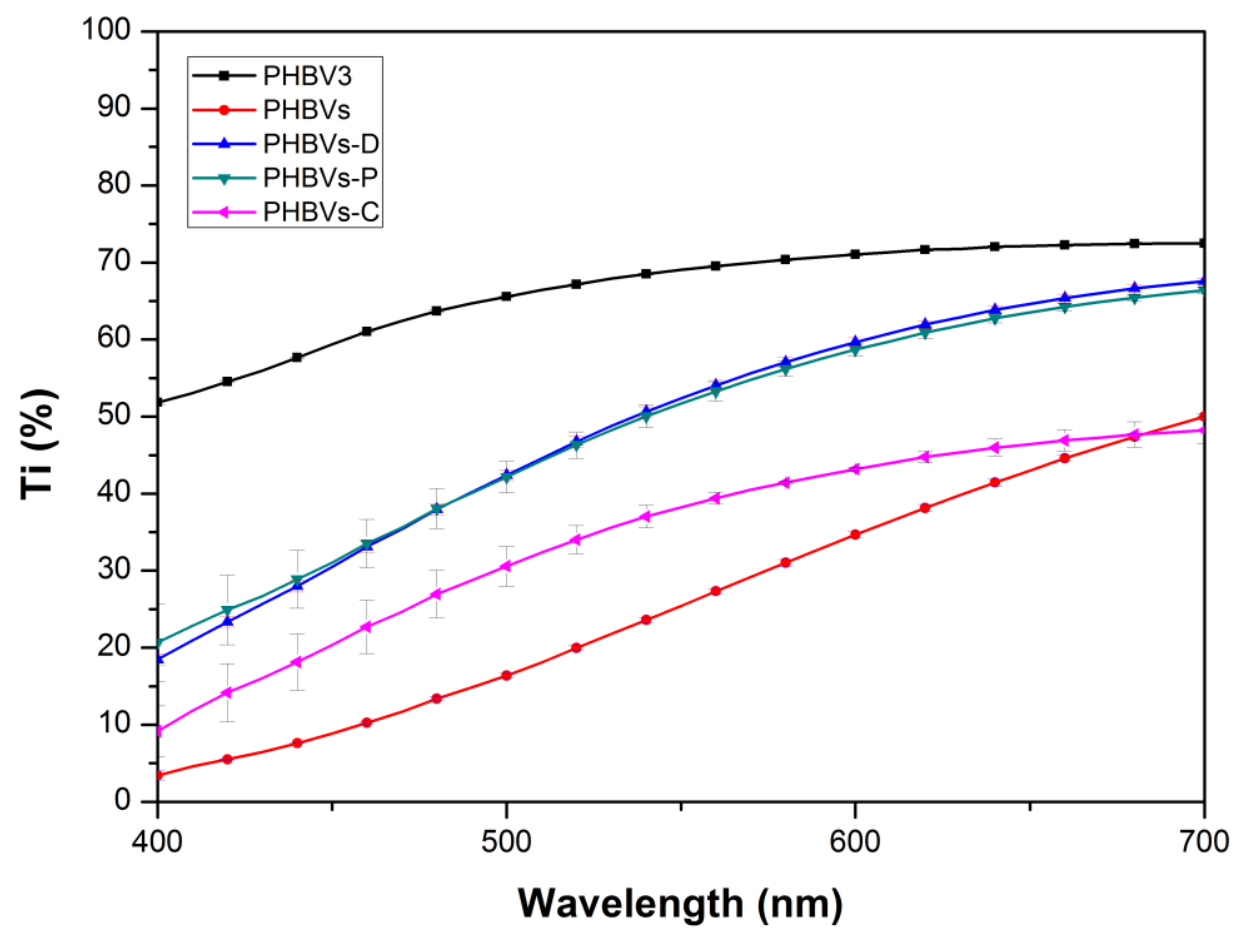

Figure 6. Spectral distribution of internal transmittance (Ti) of PHBV3, PHBVs and their $\mathrm{ZnO}$ nanocomposites.

The transparency of the films is a highly desirable property in many applications, especially in food packaging where the visual appeal of foods results in a key factor for the consumer demand and market trends. According to Hutchings (1999), transparency is the best optical property to assess the appearance of the films and it has been quantified by means of the internal transmittance (Ti) spectra. In general, high $\mathrm{Ti}$ values are related to more homogeneous and transparent films, while a decrease in these values implies films with greater opacity and thus more heterogeneous matrices. As observed, all tested films 
presented a similar pattern over the wavelength considered ( $c f$. Fig. 6), although Ti values of the nanocomposite and coating films were significantly lower (less transparent) than the neat PHBV3 matrix. This decrease in transparency is of course associated to the presence of several compounds with different refractive index such as PHBV18, $\mathrm{ZnO}$ nanoparticles and agglomerates. As can be deduced from Figure 6, the film's surface morphology and thus the type of film (nanocomposites vs. coating form), played a major role on the transparency of the films than the presence of same agglomerates of $\mathrm{ZnO}$ nanoparticles. In fact, when nanocomposites prepared by both direct and preincorporation methods were compared, no significant differences were observed between them. However, Ti values of the coating films (PHBVs-C) were significantly lower, fact that could be ascribed to an increase in the light scattering caused by the PHBV18/P-ZnO fibrous coating. As opposed to this, in the nanocomposite films a greater confinement of the PHBV18/P-ZnO into the homogeneous PHBV3 matrix was produced during the melt compounding and thus the transparency of the nanocomposites were affected to a lesser extent.

\begin{tabular}{|l|c|c|c|c|c|c|}
\hline \multicolumn{1}{|c|}{ Sample } & $\mathbf{L}^{*}$ & $\mathbf{a}^{*}$ & $\mathbf{b}^{*}$ & $\mathbf{C}_{\mathbf{a b}}{ }^{*}$ & $\mathbf{h}_{\mathbf{a b}}{ }^{*}$ & $\Delta \mathbf{E}$ \\
\hline PHBV3 & $82.3 \pm 0.4^{\mathrm{a}}$ & $1.4 \pm 0.1^{\mathrm{a}}$ & $17.7 \pm 0.0^{\mathrm{a}}$ & $17.8 \pm 0.1^{\mathrm{a}}$ & $85.5 \pm 0.7^{\mathrm{a}}$ & - \\
\hline PHBVs & $32.7 \pm 0.5^{\mathrm{b}}$ & $6.7 \pm 0.1^{\mathrm{b}}$ & $10.2 \pm 0.1^{\mathrm{b}}$ & $12.2 \pm 0.5^{\mathrm{b}}$ & $57.0 \pm 1.4^{\mathrm{b}}$ & $50.5 \pm 0.9^{\mathrm{a}}$ \\
\hline PHBVs-D & $56.9 \pm 0.4^{\mathrm{c}}$ & $9.0 \pm 0.1^{\mathrm{c}}$ & $25.3 \pm 0.1^{\mathrm{c}}$ & $26.9 \pm 0.1^{\mathrm{c}}$ & $70.0 \pm 0.0^{\mathrm{c}}$ & $27.7 \pm 0.8^{\mathrm{b}}$ \\
\hline PHBVs-P & $58.4 \pm 0.2^{\mathrm{c}}$ & $8.5 \pm 0.1^{\mathrm{c}}$ & $25.1 \pm 0.4^{\mathrm{c}}$ & $26.5 \pm 0.4^{\mathrm{c}}$ & $71.0 \pm 0.0^{\mathrm{c}}$ & $26.1 \pm 0.4^{\mathrm{b}}$ \\
\hline PHBVs-C & $72.5 \pm 2.4^{\mathrm{d}}$ & $3.8 \pm 0.6^{\mathrm{d}}$ & $24.7 \pm 2.8^{\mathrm{c}}$ & $24.9 \pm 2.8^{\mathrm{c}}$ & $79.0 \pm 2.8^{\mathrm{d}}$ & $12.3 \pm 3.3^{\mathrm{c}}$ \\
\hline
\end{tabular}

Mean values \pm standard deviation. Mean values with different letters in the same column represent significant differences (p<0.05) among the samples according to ANOVA and Tukey's multiple comparison tests.

Table 1. Colour parameters of the neat PHBV3, PHBVs and their ZnO-based nanocomposites 


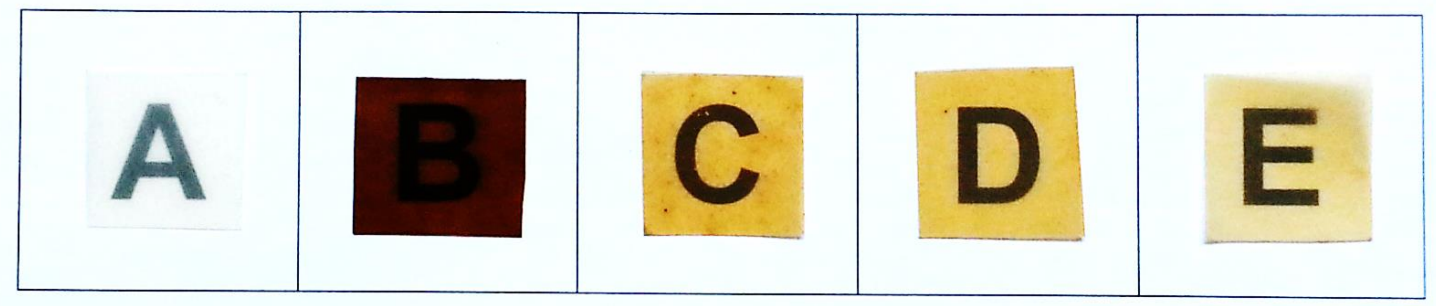

Figure 7. Detailed contact transparency pictures of PHBV3 (a), PHBVs (b) and their ZnO nanocomposites and coating structure: (c) PHBVs-D, (d) PHBVs-P, (e) PHBVs-C.

From the reflectance spectra of an infinite thickness film, lightness $\left(\mathrm{L}^{*}\right)$, hue $\left(\mathrm{h}_{\mathrm{ab}}{ }^{*}\right)$ and Chroma $\left(\mathrm{C}_{\mathrm{ab}}\right) *$ were obtained (Table 1). As deduced from Table 1 and contact transparency images (Figure 6), the first thing to highlight is that PHBV18 degraded during the meltmixing process and the appearance of the heat pressed PHBVs films (without $\mathrm{ZnO}$ nanoparticles) were darker (lower $\mathrm{L}^{*}$ ) and less vivid (lower $\mathrm{C}_{\mathrm{ab}}{ }^{*}$ ) with a brown hue indicating rather deficient optical properties. This was supported by the highest total difference values $(\Delta \mathrm{E})$ obtained for these films when they were compared to the neat PHBV3 film. The thermal instability has been ascribed to impurities from the fermentation process (close to 30 wt. \% . (Castro-Mayorga, Martínez-Abad, Fabra, Olivera, Reis, \& Lagarón)) which are thought to undergo Maillard reactions between amide groups and residual reducing sugars during the melt mixing process. Interestingly, the addition of $\mathrm{ZnO}$ improved the appearance of the developed nanocomposite and coating films and the negative effect of the unpurified PHBV18 was mitigated, as it can be easily observed in Figure 7. $\mathrm{L}^{*}$ and $\mathrm{h}_{\mathrm{ab}} *$ decreased whereas $\mathrm{C}_{\mathrm{ab}} *$ values increased for nanocomposite and coating films containing $\mathrm{ZnO}$ nanoparticles as compared to the neat PHBV3 film which means that these samples were slightly darker, less vivid and with a yellow-brown color but 
these changes were significantly lower than those obtained for PHBVs film (without ZnO nanoparticles). Accordingly, the PHBVs-D and PHBVs-P nanocomposites displayed a very similar coloration pattern between them, while PHBVs-C presented the lowest color difference $(\Delta \mathrm{E})$ as compared to the neat PHBV3. These results suggest that well dispersed and distributed $\mathrm{ZnO}$ nanoparticles may exert a stabilizing role for the unpurified PHBV18 during the melt mixing.

\subsubsection{Thermal properties}

\begin{tabular}{|l|r|r|r|r|r|}
\hline \multicolumn{1}{|c|}{ Sample } & \multicolumn{1}{c|}{$\mathbf{T}_{\mathbf{m} 1}\left({ }^{\circ} \mathbf{C}\right)$} & \multicolumn{1}{c|}{$\mathbf{T}_{\mathbf{m} 2}\left({ }^{\circ} \mathbf{C}\right)$} & \multicolumn{1}{c|}{$\mathbf{T c}\left({ }^{\circ} \mathbf{C}\right)$} & $\begin{array}{c}\Delta \mathbf{H}_{\mathbf{m}} \\
(\mathbf{J} / \mathbf{g} \mathbf{P H B V s})\end{array}$ & $\mathbf{X}(\boldsymbol{\%})$ \\
\hline PHBV3 & $168.7 \pm 1.0^{\mathrm{abc}}$ & $181.8 \pm 0.2^{\mathrm{a}}$ & $114.7 \pm 0.0^{\mathrm{a}}$ & $72 \pm 1^{\mathrm{a}}$ & $66 \pm 1^{\mathrm{a}}$ \\
\hline PHBVs & $170.9 \pm 0.1^{\mathrm{c}}$ & $182.6 \pm 0.1^{\mathrm{ab}}$ & $101.0 \pm 0.3^{\mathrm{b}}$ & $68 \pm 2^{\mathrm{a}}$ & $63 \pm 2^{\mathrm{a}}$ \\
\hline PHBVs-D & $166.9 \pm 0.5^{\mathrm{ab}}$ & - & $112.1 \pm 0.2^{\mathrm{c}}$ & $56 \pm 3^{\mathrm{b}}$ & $50 \pm 2^{\mathrm{b}}$ \\
\hline PHBVs-P & $166.5 \pm 0.4^{\mathrm{a}}$ & $183.8 \pm 0.7^{\mathrm{b}}$ & $111.6 \pm 0.3^{\mathrm{c}}$ & $58 \pm 1^{\mathrm{b}}$ & $51 \pm 1^{\mathrm{b}}$ \\
\hline PHBVs-C & $169.0 \pm 0.5^{\mathrm{bc}}$ & - & $118.0 \pm 0.6^{\mathrm{d}}$ & $39 \pm 1^{\mathrm{c}}$ & $35 \pm 1^{\mathrm{c}}$ \\
\hline
\end{tabular}

Mean values \pm standard deviation. Mean values with different letters in the same column represent significant differences $(p<0.05)$ among the samples according to ANOVA and Tukey's multiple comparison tests.

Table 2. DSC melting point $\left(T_{m}\right)$, melting enthalpy $\left(\Delta H_{m}\right)$, crystallization temperature $\left(T_{c}\right)$ and degree of crystallinity (X) of the neat PHBV3, PHBVs and their ZnO-based composites. 


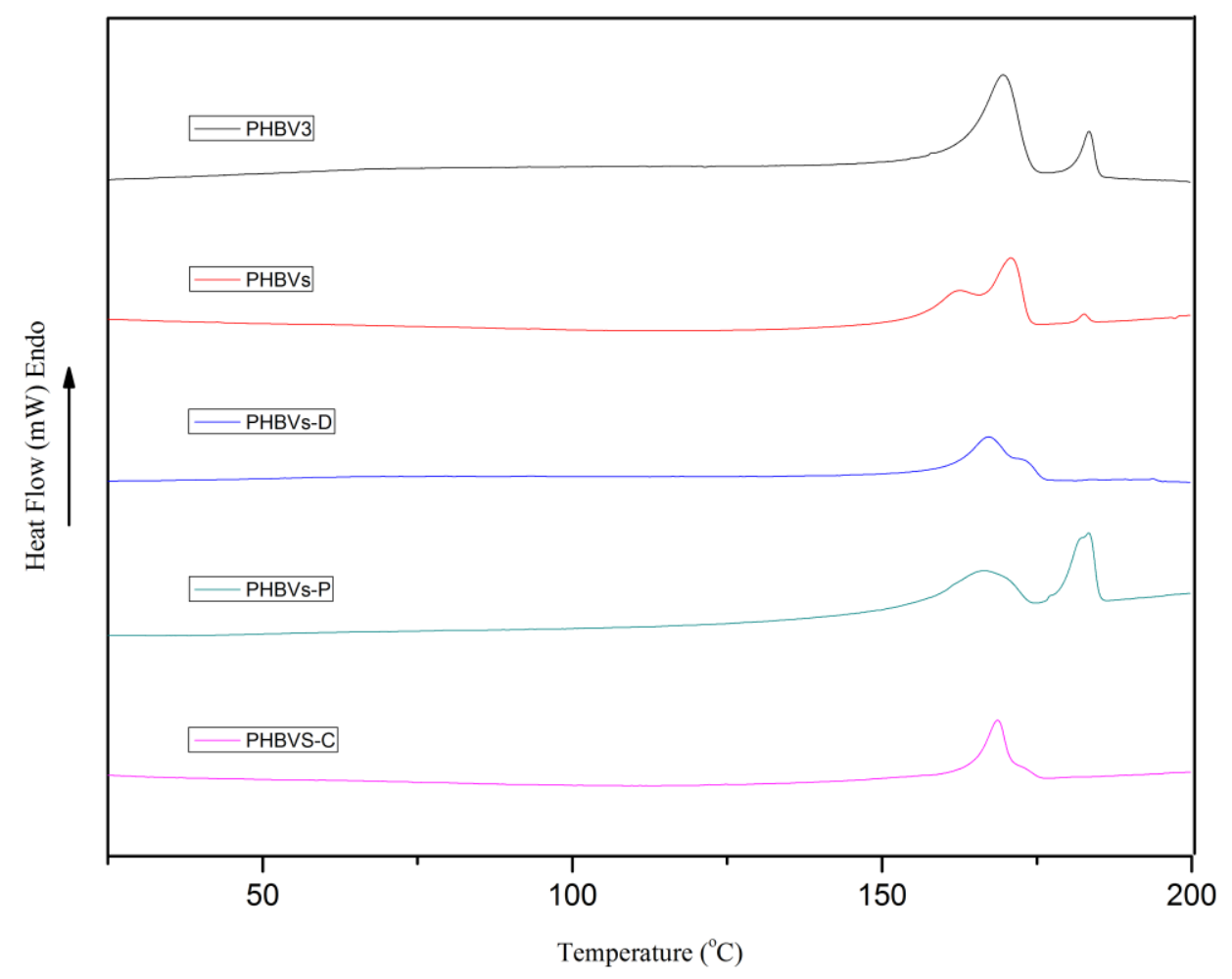

Figure 8. DSC thermograms of first heating run of the neat PHBV3, PHBVs and their ZnO-based nanocomposites.

Thermal properties of the PHBV and its active films were investigated by DSC analyses. The first heating DSC thermogram is illustrated in Figures 8 and the corresponding data are gathered in Table 2. The neat PHBV3 and PHBVs mixture presented a two-step melting behavior. The appearance of multiple melting peaks of PHBV copolymer has been previously ascribed to an effect of the melting-recrystallization process occurring during subsequent heating (Castro-Mayorga, et al.; Martínez-Sanz, et al.), which means that more defective or smaller crystals are able to recrystallize after melting forming more perfect crystals which subsequently melt at higher temperatures This statement agreed with the differences observed between the PHBV3 and PHBVs mixtures. The presence of PHBV18 
in the mixture reduced the melting enthalpy and most likely impairs crystallinity development, since there is a sharp reduction in the second melting peak and a small shoulder in the first melting peak. The PHBV18 hinders the crystallization of the PHBV3 polymer matrix probably due to both the higher hydroxyvalerate content (Serafim, Lemos, Torres, Reis, \& Ramos) and the presence of impurities as previously reported by MartinezAbad et al. (Martínez-Abad, et al.) and Castro Mayorga et al. (Castro-Mayorga, et al.).

The incorporation of $\mathrm{ZnO}$ nanoparticles by direct melt mixing (PHBVs-D) also changes the melting behavior of the PHBVs matrix in a way that suggests that $\mathrm{ZnO}$ particles hinder the recrystallization during heating. A similar melting pattern was observed between nanocomposites prepared by means of the preincorporation method and the neat PHBV3 films suggesting that this methodology does not alter the melting behavior of the PHBV3 matrix. However, it was found that the estimated crystallinity degree of the nanocomposites decreased most likely as a result of the lower crystallinity brought in by the PHBV18 polymer and also a potential antinucleation of the blending systems involved (MartínezAbad, et al.).

The incorporation of $\mathrm{ZnO}$ nanoparticles as a coating (PHBVs-C) led to a drop in the melting enthalpy with a subsequent decrease in the crystallinity degree ( $c f$. Table 2) attributed to the lower crystallinity brought in by the PHBV18. Regarding the crystallization process, a decrease in the crystallization temperature $\left(T_{c}\right)$ for the PHBVs composites as compared to PHBV3 matrix was registered in agreement with previous results reported by Martínez-Abad et al., 2015 (Martínez-Abad, et al., 2015), supporting the antinucleation effect discussed above. On the other hand, for the coating the crystallization temperate was seen to increase but very slightly. 


\begin{tabular}{|l|c|c|c|}
\hline \multicolumn{1}{|c|}{ Sample } & $\mathbf{T}_{\text {onset }}\left({ }^{\circ} \mathbf{C}\right)$ & \multicolumn{1}{c|}{$\mathbf{T}_{\mathbf{d}}\left({ }^{\circ} \mathbf{C}\right)$} & \multicolumn{1}{c|}{$\mathbf{R}_{\mathbf{4 0 0}}$} \\
\hline PHBV3 & $269.0 \pm 8.9^{\mathrm{a}}$ & $290.8 \pm 3.8^{\mathrm{a}}$ & $5.1 \pm 2.1^{\mathrm{a}}$ \\
\hline PHBVs & $270.1 \pm 7.8^{\mathrm{a}}$ & $283.1 \pm 6.5^{\mathrm{ab}}$ & $5.3 \pm 1.1^{\mathrm{a}}$ \\
\hline PHBVs-D & $256.9 \pm 2.0^{\mathrm{a}}$ & $271.3 \pm 0.9^{\mathrm{b}}$ & $15.9 \pm 3.2^{\mathrm{b}}$ \\
\hline PHBVs-P & $256.6 \pm 2.1^{\mathrm{a}}$ & $270.3 \pm 0.4^{\mathrm{b}}$ & $14.8 \pm 0.9^{\mathrm{b}}$ \\
\hline PHBVs-C & $251.8 \pm 0.2^{\mathrm{a}}$ & $270.8 \pm 3.7^{\mathrm{b}}$ & $13.3 \pm 0.1^{\mathrm{b}}$ \\
\hline
\end{tabular}

Mean values \pm standard deviation. Mean values with different letters in the same Column represent significant differences $(\mathrm{p}<0.05)$ among the samples according to ANOVA and Tukey's multiple comparison tests.

Table 3. TGA decomposition temperatures $\left(T_{d}\right)$ and the corresponding peak onset values $\left(T_{\text {onset }}\right)$ and the residue at $400{ }^{\circ} \mathrm{C}\left(R_{400}\right)$ for the neat PHBV3, PHBVs and their ZnO-based nanocomposites.

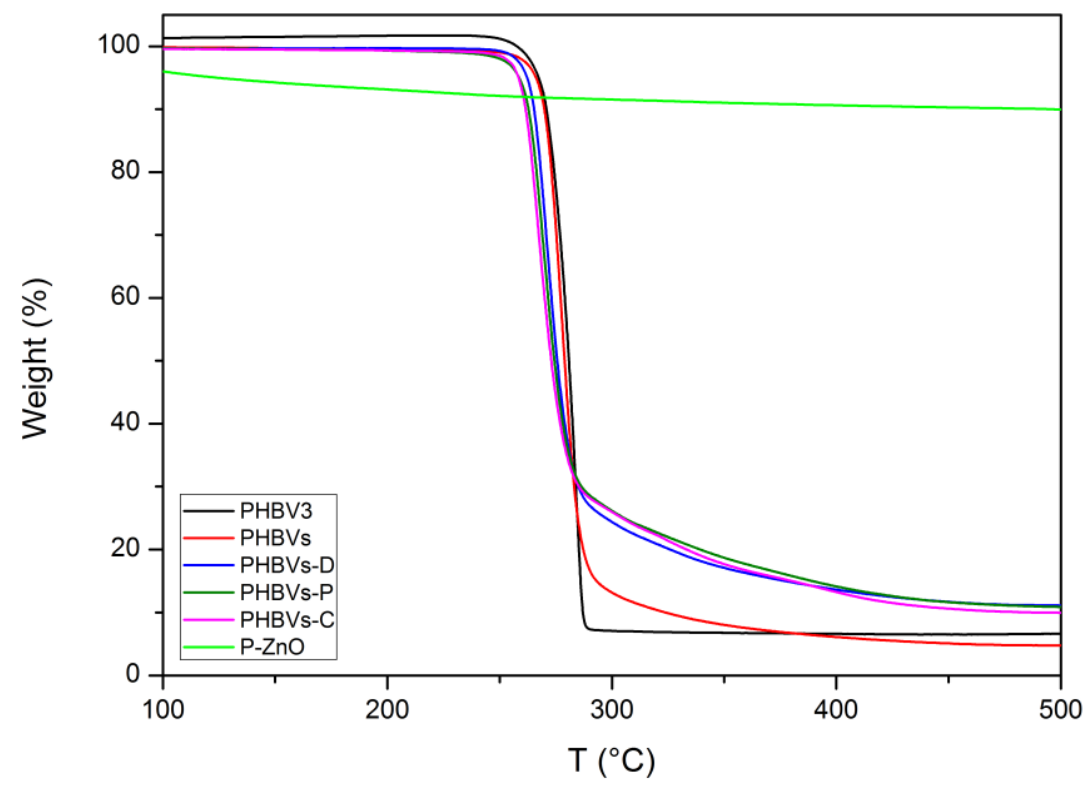

Figure 9. TGA curves of the neat PHBV3, PHBVs and their ZnO-based nanocomposites 
The thermal stability of the neat PHBV3, PHBVs and their nanocomposites and coating films was evaluated through TGA. Table 3 and Figure 9 show the TGA parameters of the tested films and the $\mathrm{P}-\mathrm{ZnO}$ nanoparticles, measured under nitrogen conditions. The $\mathrm{ZnO}$ nanoparticles display a small weight loss ( 9.4\%) below $400^{\circ} \mathrm{C}$ likely ascribed to the elimination of physically and chemically adsorbed water on their surface. In regard to the films, all of them exhibited a similar thermal decomposition process, with a single degradation stage that started at around $\sim 260^{\circ} \mathrm{C}$. However, some differences were observed at the temperature of maximum rate of degradation $\left(\mathrm{T}_{\mathrm{d}}\right)$ of PHBVs containing $\mathrm{ZnO}$ nanoparticles, which showed lower temperature than that of the pristine PHBV3. This could be attributed to the high heat conductivity and catalytic properties of $\mathrm{ZnO}$ nanoparticles. Furthermore, the residual material of $\mathrm{P}-\mathrm{ZnO}$ composites at $400^{\circ} \mathrm{C}(\mathrm{R} 400)$ was around $15 \%$ while its amount was approximately 5\% for neat PHBV3 and PHBVs. Thus the char residue could be related both to the $\mathrm{ZnO}$ content ( $\mathrm{ca} .6 \%)$ and to undecomposed material from PHBV complexed with $\mathrm{ZnO}$. This latter subject is in accordance with the positive effect of zinc oxide on optical properties showing reduced early thermal degradation in the films. In any case, TGA analyses do not match the environmental conditions occurring during melt mixing and therefore the colour changes observed after melting at $180^{\circ} \mathrm{C}$, especially those presented by the PHBV3/PHBV18 blend, must involve small degradation steps that take place without significant mass changes at the processing temperatures which are not necessarily detected by the TGA measurements. 


\subsubsection{Mass transport properties}

\begin{tabular}{|c|c|c|}
\hline Sample & WVP (Kg m/ Pa. s. m $\left.^{2}\right)$ & $\begin{array}{c}\mathrm{PO}_{2}\left(\mathrm{~m}^{3} \mathrm{~m} / \mathrm{m}^{2} . \text { s. Pa }\right) \\
80 \% \mathrm{RH}\end{array}$ \\
\hline PHBV3 & $1.10 \pm 0.02 \mathrm{e}-15^{\mathrm{a}}$ & $2.06 \pm 0.09 \mathrm{e}-19^{\mathrm{a}}$ \\
\hline PHBVs & $2.50 \pm 0.06 \mathrm{e}-15^{\mathrm{a}}(5.61 \mathrm{e}-15)$ & $3.09 \pm 0.01 \mathrm{e}^{-1} 19^{\mathrm{a}}(3.68 \mathrm{e}-19)$ \\
\hline PHBVs-D & $1.13 \pm 0.07 \mathrm{e}-14^{\mathrm{ab}}$ & $1.34 \pm 0.26 \mathrm{e}-15^{\mathrm{d}}$ \\
\hline PHBVs-P & $1.94 \pm 0.01 \mathrm{e}-15^{\mathrm{a}}$ & $1.80 \pm 0.07 \mathrm{e}-18^{\mathrm{e}}$ \\
\hline PHBVs-C & $3.17 \pm 0.73 \mathrm{e}-14^{\mathrm{c}}$ & $2.85 \pm 0.05 \mathrm{e}-18^{\mathrm{f}}$ \\
\hline PHBV18* & $1.88 \pm 0.03 \mathrm{e}-14 \mathrm{~b}$ & $8.43 \pm 0.44 \mathrm{e}-19 \mathrm{~b}$ \\
\hline
\end{tabular}

Table 4. Water vapor permeability measured at 100\% RH and oxygen permeability measured at $80 \% \mathrm{RH}$ for PHBV3, PHBVs their ZnO-based composites Values between brackets represent calculations obtained by applying the simple rule of mixtures for the PHBV3/PHBV18 composites containing 24\% of PHBV18.

Water vapour permeability and oxygen permeability are important properties which can determine the potential application of a packaging material in food preservation. Table 4 gathers the results for the neat PHBV3, the PHBVs mixture and nanocomposites/coating structures containing $\mathrm{ZnO}$ nanoparticles. The first observation to highlight is that, although the water and oxygen permeability values increase was very small (not statistically significant), a higher permeability increase was clearly expected from simple application of the rule of mixture, since the blending element (PHBV18) has higher water and oxygen permeability values. This inconsistency between the expected and the experimental results 
suggests that the blending element when confined into the more hydrophobic matrix is restricted to swell (Castro-Mayorga, Fabra, \& Lagaron).

As can be seen from Table 4, the incorporation of $\mathrm{ZnO}$ nanoparticles into PHBVs matrix led to a significant barrier decrease which can be mainly attributed to the decreased crystallinity as well as to the higher hydrophilic character of the $\mathrm{ZnO}$ as compared to the neat PHBV(Ana M. Díez-Pascual \& Angel L. Díez-Vicente).

This study is not in agreement with previous works reporting on PHBV and metallic nanoparticles composites where the addition of commercial $\mathrm{ZnO}$ increased the crystallinity and barrier properties (A. M. Díez-Pascual, et al.; Ana M. Díez-Pascual, et al.). However, this negative effect on barrier properties was limited by the good dispersion and distribution achieved with the electrospinning preincorporation method, showing no significant differences in water vapor permeability when PHBVs-P nanocomposites were compared to the neat PHBVs films. As opposed to this, the big size of agglomerates present in the PHBV-D disrupted the continuity of the PHBVs matrix causing a detrimental effect on water vapor and oxygen barrier of the nanocomposites.

In spite of the fact that the most efficient technology to improve barrier properties is a multilayer display, the coating structures did not improve barrier performance of the PHBVs which could be explained by the more hydrophilic character of the electrospun coating prepared with PHBV18/ZnO, as compared to the neat PHBV3 film used as substrate. In fact, great differences were observed in the water uptake values when the neat PHBV18 (32.1 $\pm 1.2 \%)$ and the neat PHBV3 (9.8 \pm 0.6$)$ were compared (Castro-Mayorga, et al.). 


\subsubsection{Mechanical properties}

\begin{tabular}{|c|c|c|c|}
\hline Sample & $\begin{array}{c}\text { Elastic } \\
\text { modulus } \\
(\mathbf{G P a})\end{array}$ & $\begin{array}{c}\text { Elongation } \\
\text { at break } \\
(\%)\end{array}$ & $\begin{array}{c}\text { Tensile } \\
\text { strength } \\
\text { (MPa) }\end{array}$ \\
\hline PHBV3 & $2.6 \pm 0.1^{\mathrm{a}}$ & $1.5 \pm 0.2^{\mathrm{a}}$ & $33.9 \pm 6.9^{\mathrm{a}}$ \\
\hline PHBVs & $2.2 \pm 0.2^{\mathrm{ab}}$ & $1.3 \pm 0.1^{\mathrm{a}}$ & $18.5 \pm 1.0^{b}$ \\
\hline PHBVs-D & $1.5 \pm 0.2^{\mathrm{c}}$ & $6.5 \pm 1.4^{b}$ & $12.5 \pm 1.8^{b}$ \\
\hline PHBVs-P & $2.1 \pm 0.0^{b}$ & $2.3 \pm 0.2^{\mathrm{a}}$ & $34.8 \pm 0.5^{\mathrm{a}}$ \\
\hline PHBVs-C & $1.4 \pm 0.1^{\mathrm{c}}$ & $6.2 \pm 0.5^{b}$ & $22.6 \pm 1.8^{\mathrm{ab}}$ \\
\hline
\end{tabular}

Table 5. Tensile parameters of the neat PHBV3, PHBVs their ZnO-based nanocomposites.

Mechanical properties of the neat and zinc oxide containing films are summarized in Table 5. From these results, it may be deduced that the mechanical properties were mainly affected by the presence of $\mathrm{ZnO}$ nanoparticles and the methodology used, but not so greatly by valerate content. Thus, PHBVs films showed similar rigidity and brittleness than the neat PHBV3 but lower strength. The small differences between the unfilled matrices (without $\mathrm{ZnO}$ nanoparticles) can be explained by the presence of a high concentration of non-polymeric impurities, derived from the fermentation process of PHBV18 that could act as stress concentration moieties (Martínez-Abad et al., 2015). In fact, Martínez-Abad et al., 2015 reported that EAB values of samples containing more than $15 \mathrm{wt}$. $\%$ of the PHBV18 did not significantly differ from the neat PHBV3 although the tensile strength slightly decreased. 
Considering the data corresponding to the methodology used during films' preparation, the greater ductility of the PHBVs-D and PHBVs-C structures was evidenced by their significantly reduced Young's modulus and increased elongation at break. Besides, the addition of PHBV18 and $\mathrm{ZnO}$ nanoparticles directly in the melt mixing step or in a coating form, led to a decrease in the energy absorbed by the material at break (i.e. toughness). However, the electrospinning preincorporation method did not modify the elongation and stiffness of the neat PHBV3 probably due to the higher dispersion of the PHBV18/ZnO fibers into the PHBV3 matrix, fact that also explained the small differences observed in thermal and water vapor barrier properties. It is known that the mobility of the filler within the polymeric matrix together with the nanoparticle alignment under an applied tensile stress is essential for energy dissipation and, thus, the toughness (A. M. Díez-Pascual, et al.; Ana M. Díez-Pascual, et al.). Hence, once again, it appears that a greater dispersion and distribution of the nanoparticles was achieved in the PHBVs-P system. 


\subsubsection{Antimicrobial activity of active PHBV films}

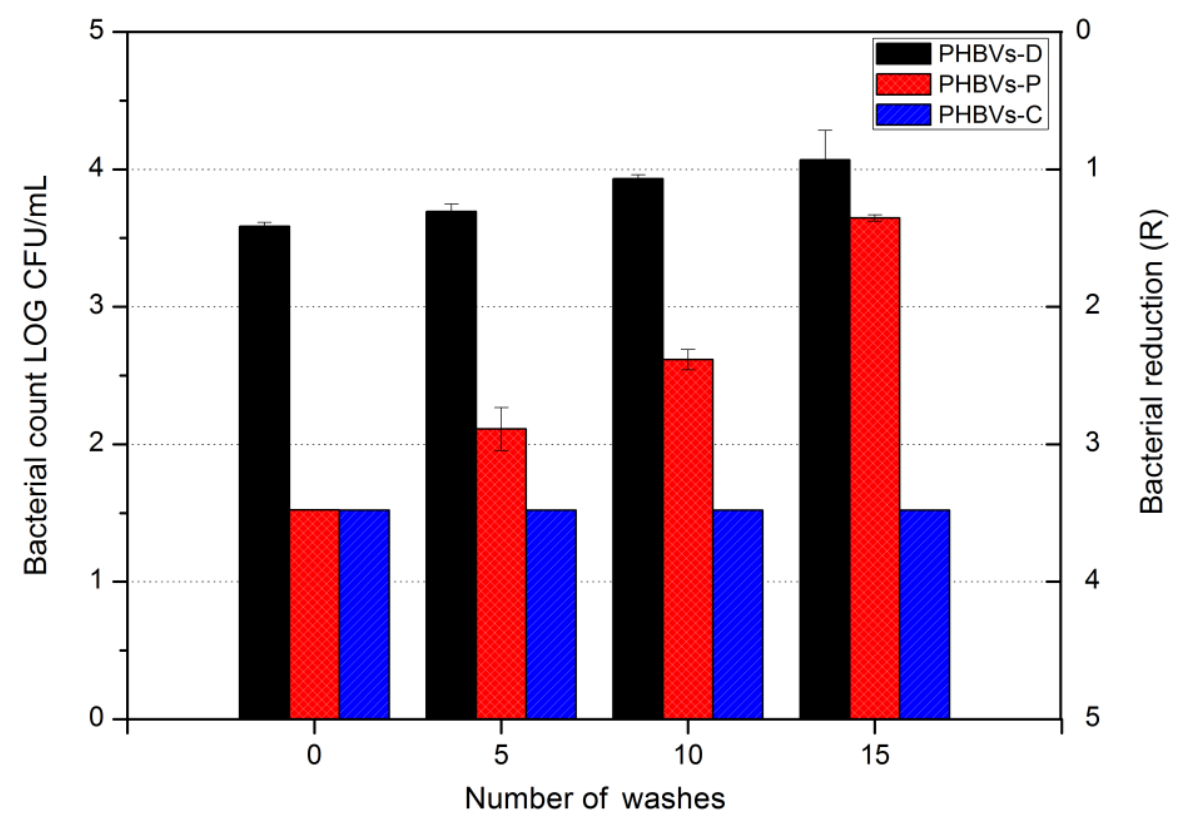

Figure 10. Antimicrobial activity of PHBVs-ZnO films against Listeria monocytogenes after successive washes. The initial inoculum size was $5 \log \mathrm{CFU} / \mathrm{mL}$ and the detection limit was $20 \mathrm{CFU} / \mathrm{mL}$.

Given that the $\mathrm{P}-\mathrm{ZnO}$ nanoparticles demonstrated high antimicrobial performance against Listeria monocytogenes in liquid media, they were incorporated in PHBV films following the methodology described above. In order to ascertain if the release of $\mathrm{ZnO}$ nanoparticles may be sufficiently sustained as to allow a continuous effect, the antimicrobial activity of the obtained films was assessed after successively washing and the zinc concentration in the washing solution was quantified by ICP-OES. 
As indicated by Figure 10, before the washes, a bactericidal effect, that is, a reduction of 3 CFU log units compared to the initial inoculum was recorded for active films prepared by preincorporation and coating systems while, for films prepared by direct addition, a lower bacterial reduction of $1 \log \mathrm{CFU}$ was achieved. This indicates the potential of antimicrobial $\mathrm{ZnO}$ nanoparticles is being more efficiently exploited when incorporated in the electrospun fibers, which promotes improved dispersion and distribution of the nanoparticles in the polymer matrix.

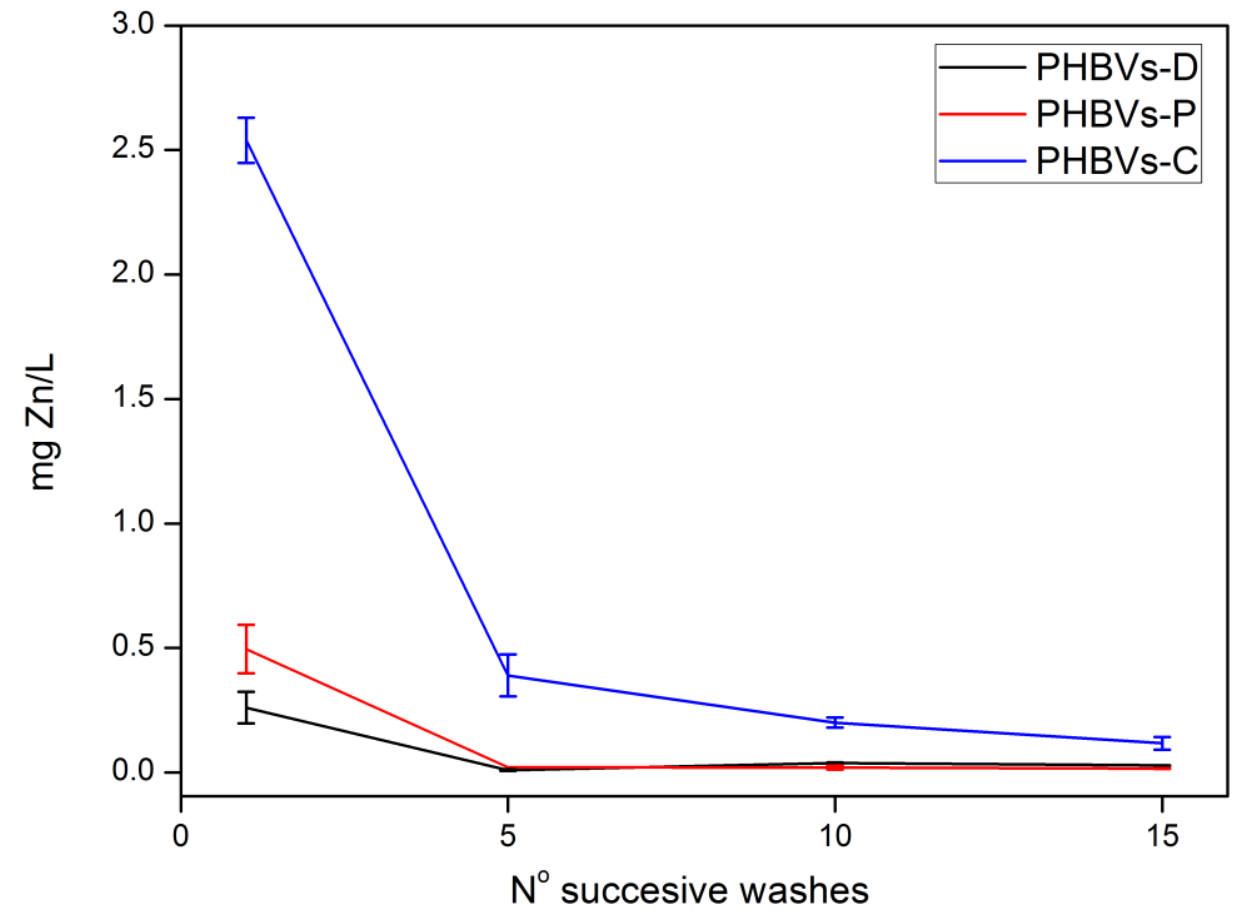

Figure 11. Release profile of zinc of PHBVs-ZnO films after successive washes.

After successively washes, the antimicrobial efficacy of PHBVs-D and PHBVs-P decreased gradually as a consequence of the zinc release from the film surface to the water washing. These results were in line with the zinc concentration profile obtained by ICP-OES where a 
burst release regime was registered in the fifth wash (Figure 11). Interestingly, no viable cells were detected in PHBVs-C films even after 15 washes. These results demonstrate that the zinc oxide containing fibers mat placed as coating in the outer layer of the coating structure increased the zinc availability and, thus, its antimicrobial performance.

On the other hand, from the ICP-OES results it is important to highlight that the released zinc detected in the washing water after 15 washes for all tested films was very low as compared to the $6 \%$ initial load. Therefore, it can be also concluded that the zinc oxide nanoparticles incorporated into the bulk of PHBV3 matrix (i.e. those films prepared by direct melt mixing or preincorporation method) could not migrate to the surface in contact with the bacterial suspension. Once the zinc available at the surface of PHBVs-D and PHBVs-P films was released along the first five washes, it was not replaced and its bactericidal effect was lost. In the case of the coating system (PHBVs-C), although the burst release also occurred in the first five washes, the amount of zinc available in the film surface was enough to lead a prolonged and effective antimicrobial activity.

Considering the specific migration limit imposed by European Union Guidelines on Regulation (EU) No 10/2011 on plastic materials and articles intended to come into contact with food for zinc $(25 \mathrm{mg} / \mathrm{kg}$ food), under the test washing conditions, even when the burst release took place, the zinc release from in any of the assessed films did not surpass the current restriction limits. However, additional research on the behaviour of these active films in other food simulants or food matrices according to current legislation is required to ascertain its ultimate implementation in food packaging applications. 


\section{CONCLUSIONS}

Nanotechnology is an interesting field of science offering materials exhibiting unique properties such as enhanced antimicrobial activity against food borne pathogens. The present work shows the great potential of the nanostructured $\mathrm{ZnO}$ as antimicrobial material for active food packaging applications. In the first part of this study, it was observed that the antibacterial effect of $\mathrm{ZnO}$ particles was significantly improved when the specific surface area of particles increased, being the hexagonal-pyramid nanoparticles (P-ZnO) those that presented the highest antibacterial effect. Moreover, these nanoparticles maintained their antimicrobial activity even when they were incorporated in coating PHBV structures. In addition to their antimicrobial properties, $\mathrm{ZnO}$ nanoparticles presented a positive effect on thermal stability and optical properties of active films avoiding their browning after thermal processing. Although some research works have previously demonstrated the reinforcing effect of $\mathrm{ZnO}$ nanoparticles in terms of barrier and mechanical properties when they are incorporated into biopolymeric matrices, the high amounts of the PHBV18/ZnO required to obtain a bactericide effect against $L$. monocytogenes, negatively affected the performance of the material. It is important to highlight that barrier properties depend on the product features and the intended end-used application. For instance, in packages for fresh fruits and vegetables, high barrier to oxygen diffusion are undesirable and modified atmosphere packaging should have a high oxygen barrier. Finally, the results show that aqueous prepared inorganic metal oxide nanoparticles with desirably exposed crystal surfaces' provides an efficient tool for the making of functional antimicrobial nanocomposites within food packaging. 


\section{ACKNOWLEDGMENTS}

The authors are thankful to Dr. Maria Reis from Universidade Nova de Lisboa, and Dr.

Catarina Oliveira, from Centro de Quimica fina e Biotecnologia, for the synthesis of

PHBV18 and Dr. Luis Cabedo, from Universitat Jaume I for his support with mechanical testing. This work was financially supported by the Spanish Ministry of Economy and Competitiveness (MAT2012-38947-C02-01 and AGL2015-63855-C2-1-R). J.L. Castro-

Mayorga is supported by the Administrative Department of Science, Technology and Innovation (Colciencias) of Colombian Government. M. J. Fabra is recipient of a Ramon y Cajal contract from the Spanish Ministry of Economy and Competitiveness.

\section{REFERENCES}

Arakha, M., Saleem, M., Mallick, B. C., \& Jha, S. (2015). The effects of interfacial potential on antimicrobial propensity of $\mathrm{ZnO}$ nanoparticle. Sci. Rep., 5.

Brayner, R., Ferrari-Iliou, R., Brivois, N., Djediat, S., Benedetti, M. F., \& Fiévet, F. (2006). Toxicological Impact Studies Based on Escherichia coli Bacteria in Ultrafine ZnO Nanoparticles Colloidal Medium. Nano Letters, 6(4), 866-870.

Castro-Mayorga, J. L., Fabra, M. J., \& Lagaron, J. M. Stabilized nanosilver based antimicrobial poly(3-hydroxybutyrate-co-3-hydroxyvalerate) nanocomposites of interest in active food packaging. Innovative Food Science \& Emerging Technologies.

Castro-Mayorga, J. L., Martínez-Abad, A., Fabra, M. J., Olivera, C., Reis, M., \& Lagarón, J. M. (2014). Stabilization of antimicrobial silver nanoparticles by a polyhydroxyalkanoate obtained from mixed bacterial culture. International Journal of Biological Macromolecules, 71, 103-110.

Díez-Pascual, A. M., \& Díez-Vicente, A. L. (2014). Poly(3-hydroxybutyrate)/ZnO bionanocomposites with improved mechanical, barrier and antibacterial properties. International Journal of Molecular Sciences, 15(6), 10950-10973.

Díez-Pascual, A. M., \& Díez-Vicente, A. L. (2014). ZnO-Reinforced Poly(3hydroxybutyrate-co-3-hydroxyvalerate) Bionanocomposites with Antimicrobial Function for Food Packaging. ACS Applied Materials \& Interfaces, 6(12), 98229834.

Djurišić, A. B., Leung, Y. H., Ng, A. M. C., Xu, X. Y., Lee, P. K. H., Degger, N., \& Wu, R. S. S. (2015). Toxicity of metal oxide nanoparticles: Mechanisms, characterization, and avoiding experimental artefacts. Small, 11(1), 26-44. 
Emamifar, A., Kadivar, M., Shahedi, M., \& Soleimanian-Zad, S. (2010). Evaluation of nanocomposite packaging containing $\mathrm{Ag}$ and $\mathrm{ZnO}$ on shelf life of fresh orange juice. Innovative Food Science \& Emerging Technologies, 11(4), 742-748.

Espitia, P., Soares, N. d., Coimbra, J. d., de Andrade, N., Cruz, R., \& Medeiros, E. (2012). Zinc Oxide Nanoparticles: Synthesis, Antimicrobial Activity and Food Packaging Applications. Food and Bioprocess Technology, 5(5), 1447-1464.

Fabra, M. J., Lopez-Rubio, A., \& Lagaron, J. M. (2013). High barrier polyhydroxyalcanoate food packaging film by means of nanostructured electrospun interlayers of zein. Food Hydrocolloids, 32(1), 106-114.

Gurlo, A. (2011). Nanosensors: Towards morphological control of gas sensing activity. $\mathrm{SnO} 2, \mathrm{In} 2 \mathrm{O} 3, \mathrm{ZnO}$ and $\mathrm{WO} 3$ case studies. Nanoscale, 3(1), 154-165.

Han, J. H. (2000). Antimicrobial Food Packaging. Food Technology, 54(3), 56-65.

Li, B., \& Wang, Y. (2010). Facile synthesis and enhanced photocatalytic performance of flower-like $\mathrm{ZnO}$ hierarchical microstructures. Journal of Physical Chemistry C, 114(2), 890-896.

Martínez-Abad, A., Cabedo, L., Oliveira, C. S. S., Hilliou, L., Reis, M., \& Lagarón, J. M. (2015). Characterization of polyhydroxyalkanoate blends incorporating unpurified biosustainably produced poly(3-hydroxybutyrate-co-3-hydroxyvalerate. Journal of Applied Polymer Science.

Martínez-Sanz, M., Villano, M., Oliveira, C., Albuquerque, M. G. E., Majone, M., Reis, M., Lopez-Rubio, A., \& Lagaron, J. M. (2014). Characterization of polyhydroxyalkanoates synthesized from microbial mixed cultures and of their nanobiocomposites with bacterial cellulose nanowhiskers. New Biotechnology, 31(4), 364-376.

Naphade, R., \& Jog, J. (2012). Electrospinning of PHBV/ZnO membranes: Structure and properties. Fibers and Polymers, 13(6), 692-697.

Ozdemir, M., \& Floros, J. D. (2004). Active food packaging technologies. Critical Reviews in Food Science and Nutrition, 44(3), 185-193.

Plackett, D., \& Siró, I. (2011). Polyhydroxyalkanoates (phas) for food packaging. In Multifunctional and Nanoreinforced Polymers for Food Packaging (pp. 498-526).

Pourrahimi, A. M., Liu, D., Pallon, L. K. H., Andersson, R. L., Martínez Abad, A., Lagarón, J. M., Hedenqvist, M. S., Ström, V., Gedde, U. W., \& Olsson, R. T. (2014). Water-based synthesis and cleaning methods for high purity $\mathrm{ZnO}$ nanoparticles-comparing acetate, chloride, sulphate and nitrate zinc salt precursors. RSC Advances, 4(67), 35568-35577.

Pourrahimi, A. M., Liu, D., Ström, V., Hedenqvist, M. S., Olsson, R. T., \& Gedde, U. W. (2015). Heat treatment of $\mathrm{ZnO}$ nanoparticles: new methods to achieve high-purity nanoparticles for high-voltage applications. Journal of Materials Chemistry A, 3(33), 17190-17200.

Scandola, M., Focarete, M. L., Adamus, G., Sikorska, W., Baranowska, I., Świerczek, S., Gnatowski, M., Kowalczuk, M., \& Jedliński, Z. (1997). Polymer Blends of Natural Poly(3-hydroxybutyrate-co-3-hydroxyvalerate) and a Synthetic Atactic Poly(3hydroxybutyrate). Characterization and Biodegradation Studies. Macromolecules, 30(9), 2568-2574.

Serafim, L. S., Lemos, P. C., Torres, C., Reis, M. A. M., \& Ramos, A. M. (2008). The influence of process parameters on the characteristics of polyhydroxyalkanoates produced by mixed cultures. Macromolecular Bioscience, 8(4), 355-366. 
Talebian, N., Amininezhad, S. M., \& Doudi, M. (2013). Controllable synthesis of ZnO nanoparticles and their morphology-dependent antibacterial and optical properties. Journal of Photochemistry and Photobiology B: Biology, 120, 66-73.

Vidic, J., Stankic, S., Haque, F., Ciric, D., Le Goffic, R., Vidy, A., Jupille, J., \& Delmas, B. (2013). Selective antibacterial effects of mixed $\mathrm{ZnMgO}$ nanoparticles. Journal of Nanoparticle Research, 15(5), 1595.

Yu, W., Lan, C.-H., Wang, S.-J., Fang, P.-F., \& Sun, Y.-M. (2010). Influence of zinc oxide nanoparticles on the crystallization behavior of electrospun poly(3-hydroxybutyrateco-3-hydroxyvalerate) nanofibers. Polymer, 51(11), 2403-2409. 